NBER WORKING PAPER SERIES

\title{
THE EVOLUTION OF ECONOMIC UNDERSTANDING AND POSTWAR STABILIZATION POLICY
}

\author{
Christina D. Romer \\ David H. Romer \\ Working Paper 9274 \\ http://www.nber.org/papers/w9274
NATIONAL BUREAU OF ECONOMIC RESEARCH
1050 Massachusetts Avenue
Cambridge, MA 02138
October 2002

\begin{abstract}
We are grateful to Stanley Fischer, Donald Kohn, Laurence Meyer, Michael Prell, Thomas Sargent, and Lawrence Summers for helpful comments and suggestions, and to the National Science Foundation for financial support. The views expressed herein are those of the authors and not necessarily those of the National Bureau of Economic Research.

(C) 2002 by Christina D. Romer and David H. Romer. All rights reserved. Short sections of text, not to exceed two paragraphs, may be quoted without explicit permission provided that full credit, including (C) notice, is given to the source.
\end{abstract}


The Evolution of Economic Understanding and Postwar Stabilization Policy

Christina D. Romer and David H. Romer

NBER Working Paper No. 9274

October 2002

JEL No. E60, E50, E30, N12

\section{ABSTRACT}

There have been large changes in the conduct of aggregate demand policy in the United States over the past fifty years. This paper shows that these changes in policy have resulted largely from changes in policymakers' beliefs about the functioning of the economy and the effects of policy. We document the changes in beliefs using contemporaneous discussions of the economy and policy by monetary and fiscal policymakers and, for the period since the late 1960s, using the Federal Reserve's internal forecasts. We find that policymakers' understanding of the economy has not exhibited steady improvement. Instead, the evidence reveals an evolution from a fairly crude but basically sound worldview in the 1950s, to a more sophisticated but deeply flawed model in the 1960 s, to uncertainty and fluctuating beliefs in the 1970s, and finally to the modern worldview of the 1980s and 1990s. We establish a link between policymakers' beliefs and aggregate demand policy by examining narrative evidence on the motivation for key policy choices. We also compare monetary policymakers' choices with the implications of a modern estimated policy rule and show that the main differences are consistent with the changes in beliefs that we observe.

\author{
Christina D. Romer \\ Department of Economics \\ University of California, Berkeley \\ Berkeley, CA 94720-3880 \\ and NBER \\ cromer@econ.berkeley.edu
}

\author{
David H. Romer \\ Department of Economics \\ University of California, Berkeley \\ Berkeley, CA 94720-3880 \\ and NBER \\ dromer@econ.berkeley.edu
}




\section{INTRODUCTION}

Over the past fifty years there have been large changes in aggregate demand policy in the United States, and, as a consequence, substantial changes in economic performance. In the 1950s, monetary and fiscal policy were somewhat erratic, but moderate and aimed at low inflation. As a result, inflation was indeed low and recessions were frequent, but mild. In the 1960s and 1970s, both monetary policy and fiscal policy were used aggressively to stimulate and support rapid economic growth, and for much of the period unemployment was remarkably low. But inflation became a persistent problem and periodic severe recessions were necessary to keep inflation in check. In the 1980s and 1990s, aggregate demand policy became more temperate and once again committed to low inflation. Not surprisingly, inflation has been firmly under control for almost twenty years now and the American economy experienced two decade-long expansions at the end of the twentieth century, interrupted only by one of the mildest postwar recessions.

Given the consequences of these changes in policy, it is important to understand what has caused them. Our contention is that the fundamental source of changes in policy has been changes in policymakers' beliefs about how the economy functions. We find that while the basic objectives of policymakers have remained the same, the model or framework they have used to understand the economy has changed dramatically. There has been, as our title suggests, an evolution of economic understanding. However, the evolution of economic understanding that has occurred is not one of linear progression from less knowledge to more. Rather, it is a more interesting evolution from a crude but fundamentally sensible model of how the economy worked in the 1950 s, to more formal but faulty models in the 1960s and 1970s, and finally to a model that was both sensible and sophisticated in the 1980s and 1990s.

The evolution of economic understanding fundamentally changed what policymakers believed aggregate demand policy could accomplish. In the 1950s, policymakers had a sensible view of potential 
output and a model of the economy in which inflation certainly did not lower long-run unemployment and quite possibly raised it. As a result, they believed that the most aggregate demand policy could do was keep output close to potential and inflation low. In the early 1960s, policymakers adopted the view that very low unemployment was an attainable long-run goal and that there was a permanent tradeoff between inflation and unemployment. This view led them to believe that expansionary policy could permanently reduce unemployment with little cost. In the 1970s, monetary and fiscal policymakers acknowledged the fundamental insight of the Friedman-Phelps natural-rate hypothesis - in the long run, expansionary policy only produces higher inflation; it does not lower unemployment below the natural rate. But for much of the decade, estimates of the natural rate were so low that policymakers continued to believe that further expansion would improve economic performance. Also, policymakers were so pessimistic about the ability of high unemployment to reduce inflation that they largely disavowed the conventional inflationcontrol policies of monetary and fiscal contraction. Only at the end of the decade was the FriedmanPhelps framework coupled with a realistic view of the natural rate and faith that slack would eventually reduce inflation. As a result, policymakers in the last two decades of the twentieth century believed that policy could bring inflation down, and then keep it low by holding output close to potential.

We document this evolution of economic understanding in two ways. First, we consider narrative evidence. In particular, we use the records of the Council of Economic Advisers and the Federal Reserve to examine the model of the economy underlying the actions of fiscal and monetary policymakers in various eras. We find strong evidence that the model used by policymakers changed dramatically over the postwar era. In particular, there were fundamental changes in the 1960s and 1970s. However, perhaps the most interesting characteristic of this evolution of beliefs is that core beliefs ended the century at much the same point that they began the postwar era.

Second, we look at the Federal Reserve's internal forecasts, the "Greenbook" forecasts. We examine both the forecast errors for inflation and the estimates of the natural rate of unemployment implicit in the forecasted behavior of inflation and unemployment. We find that the forecasts of inflation were consistently too low in the 1960s and 1970s, but improved dramatically in the 1980s and 1990s. 
Even more tellingly, we find that the Federal Reserve's forecasts of inflation and unemployment in the late 1960 s and the 1970s are consistent with a natural-rate model only if one assumes an extremely low natural rate, while the implicit estimates of the natural rate in the Volcker and Greenspan years are much more reasonable. This suggests that the Board staff in the 1960s and 1970s (and presumably the policymakers for whom they worked) had implausible estimates of the natural rate, or, for at least part of the period, little concept of a natural rate at all.

We then consider the link between this evolution of economic understanding and policy. We look at two key measures of aggregate-demand policy - the real federal funds rate and the highemployment surplus. We present narrative evidence that movements in these policy indicators in key periods were motivated by the economic model being used by policymakers at the time. We find, for example, that policymakers in the late 1950s undertook aggressive monetary contraction because they felt that inflation was very costly. On the other hand, policymakers in the late 1960s and early 1970s adopted very expansionary policies because they were convinced that unemployment was above its sustainable level. And later in the 1970s, policymakers looked to non-standard remedies for inflation, such as wage and price controls and incomes policies, because they were so pessimistic about the effectiveness of slack in reducing inflation. In contrast, after 1979 policymakers pursued very tight policy because they were convinced that the natural rate of unemployment was relatively high, that slack was necessary to reduce inflation, and that the costs of inflation were substantial.

We supplement this narrative analysis of the link between beliefs and policy actions with estimates of a simple monetary policy rule. We compare the predicted values of a rule estimated over the post-1979 period with what actually happened in the first three decades of the postwar era. The estimates suggest that had Paul Volcker or Alan Greenspan been confronted with the inflation of the late 1960s and 1970s, they would have set the real federal funds rate nearly four percentage points higher than did Arthur Burns and G. William Miller. On the other hand, William McChesney Martin set interest rates on average in the 1950s in much the same way Volcker or Greenspan would have, though with substantially 
larger variation. This suggests that the economic beliefs of the 1960s and 1970s resulted in policy choices very different from those that came either before or after.

The idea that policymakers' beliefs affect the conduct of policy is obviously an old one. The previous studies most directly related to ours are those by DeLong (1997) and Mayer (1998). Both authors use historical evidence to investigate the causes of the inflation of the late 1960s and the 1970s. DeLong argues that the legacy of the Great Depression imparted an expansionary bias to views of appropriate policy, and thereby made it inevitable that there would be inflation at some point. Mayer argues that the influence of academic economists' ideas on monetary policymakers' views was central to the inflation. 1 Our focus is both narrower and broader than DeLong's and Mayer's. It is narrower in that we concentrate on documenting policymakers' beliefs and their impact on policy choices, but do not attempt to address the issue of the sources of those beliefs. Our evidence supports DeLong's and Mayer's contentions that policymakers had highly optimistic views of sustainable output and unemployment in the 1960s and early 1970s, and that they were skeptical of the ability of aggregate demand policies to combat inflation for much of the 1970s. Our focus is broader than DeLong's and Mayer's in that we look at the entire postwar period and examine the beliefs of fiscal as well as monetary policymakers. In doing so, we put the beliefs of monetary policymakers in the late 1960s and 1970s in context, and provide wider evidence of the impact of beliefs on policy choices.

\section{NARRATIVE EVIDENCE ON THE EVOLUTION OF ECONOMIC BELIEFS}

Perhaps the best way to determine what policymakers in different eras believed about how the economy worked is to examine the narrative record. Policymakers are often required (or simply desire) to explain the motivations for their policy actions. By analyzing their views about the economic conditions and relationships that warranted policy actions, it is often possible to get a sense of policymakers' understanding of the economy at the time decisions were made. 


\section{A. $\underline{\text { Sources }}$}

Contemporaneous discussions of economic relationships are typically a better indicator of the framework being used at the time than interviews or memoirs written years later. Subsequent economic developments and changes in economic theory cannot help but alter recollections of the economic models that were used in the past. For this reason we restrict our analysis to policy discussions around the times that actions were taken. The two main contemporaneous sources that we examine are the Economic $\underline{\text { Report of the President and the Minutes of the Federal Open Market Committee. }}$

The Economic Report of the President (abbreviated in subsequent citations as EROP) is available twice a year in the early 1950 s and annually thereafter. Since the executive branch plays a crucial role in setting the fiscal policy agenda, the Economic Reports can provide evidence of the model of the economy being used by fiscal policymakers in different eras. And indeed, we find that the Economic Reports are often quite detailed in their discussion of economic relationships. The key disadvantage of the Economic $\underline{\text { Reports }}$ is that they are designed for public distribution, and so they surely contain elements of selectivity and circumspection. But, the prospect of public scrutiny may also tend to limit the publication of economic claims that policymakers did not actually believe.

The Minutes of the Federal Open Market Committee (abbreviated as Minutes in subsequent citations) are detailed summaries of the discussions at FOMC meetings. The Minutes were kept through mid-1976, and were replaced with verbatim Transcripts of Federal Open Market Committee meetings (abbreviated as Transcripts). The Transcripts are currently available for 1981 to 1996 . These two sources obviously provide insight into what members of the Federal Reserve's key policymaking committee believed about economic relationships in various eras. While members of the FOMC rarely frame their remarks in terms of economic models or theories, their statements often provide insight into how they believe the economy works. One obvious benefit of the Minutes is that they were not intended for broad public dissemination. For the first part of the postwar period, the FOMC intended them to be confidential; later the Committee adopted a policy of releasing the Minutes with a five-year lag. Thus, members of the FOMC could be fairly frank in their comments. We also use the brief, rapidly released 
summaries of FOMC meetings contained in the Record of Policy Actions of the Federal Open Market Committee (abbreviated as RPA). 2 These short summaries are helpful for directing our reading of the Minutes and for giving a sense of what contemporary observers and participants thought were the key issues and the essence of the discussion.

\section{B. The 1950s}

Monetary and fiscal policymakers in the 1950s held similar views about how the economy worked. One feature of the 1950s model was a realistic view of capacity and full employment. Policymakers believed that inflation began to rise at moderate rates of overall unemployment. A more important feature of the model was a definite belief that attempting to push the economy above full employment would be self-defeating. Such policies would lead to inflation, which would in turn lower long-term growth and possibly precipitate a recession. Thus, if anything, the 1950 s model held that there was a positive long-run relationship between inflation and unemployment.

The notion that there was a level of production and employment above which wages and prices started to rise was well accepted in the 1950s. For example, in 1955 one FOMC member said, "The economy was moving nearer capacity in many respects, and as this point approached less efficient means of production would be utilized and prices would tend to rise" (Minutes, 10/4/55, p. 8). Similarly, the 1957 Economic Report stated: "When production, sales, and employment are high, wage and price increases in important industries create upward pressure on costs and prices generally" (EROP, 1957, p. 44). In describing what happened in 1955, the 1956 Economic Report gave a detailed description of why prices rise at high employment. It stated:

The increase of overtime at premium rates of pay, higher wage rates and fringe benefits, greater resort by business firms to older and less efficient units of equipment in order to meet the pressing requirements of their customers, and the growing difficulties in finding suitable workers, all served to increase unit labor costs. Their advance ... exerted persistent and increasing pressure on both profit margins and prices. (EROP, 1956, p. 23) 
The level of unemployment at which 1950s policymakers thought these effects would result was not particularly low. In August 1955, one member of the FOMC indicated that at the current rate of unemployment rate of $4 \%::^{-1}$

We can all agree that the economic situation is ebullient and presses on the comfortable capacity of the economy. It can thus be concluded that the apparent present trends in the economy simply extend themselves to over-reach comfortable capacity and that, accordingly, an inflation is inevitable. (Minutes, $8 / 2 / 55$, p. 23)

The 1956 Economic Report suggested a similar view when it discussed "the attainment of practically full employment in the Nation at large" during the previous year (EROP, 1956, p. v). "Practically full employment" was the term used in the 1950s Economic Reports for the lowest sustainable rate of unemployment, and in 1955 the average unemployment rate was 4.4\%. In 1959, the chief economist of the Board of Governors said that "[t]he economy is approaching the limits of resource utilization" when the current unemployment rate was 5\% (Minutes, 6/16/59, p. 6). The 1958 Economic Report, while not giving a specific number, expressed a particularly cogent view of full employment. It discussed the likely scenario "[w] hen economic resources are close to being fully used, even though there may be slack in some sectors of the economy" (EROP, 1958, p. 3).

More interesting than the realistic notion of capacity are the beliefs policymakers in the $1950 \mathrm{~s}$ held about what would happen if aggregate demand policy tried to push unemployment below its full employment level. The most optimistic belief was that the effort would have no impact on unemployment and would only cause inflation to increase. The 1958 Economic Report, after giving the sensible definition of full employment above, continued: "Efforts to accelerate growth under these conditions may succeed only in generating inflationary pressures" (EROP, 1958, p. 4).

A much more common view was that the inflation that would result from overexpansion would eventually raise unemployment, not lower it. Federal Reserve Chairman William McChesney Martin said in 1958:

If inflation should begin to develop again, it might be that the number of unemployed would be temporarily reduced to four million [from the current level of five million], or some figure in that range, but there would be a larger amount of unemployment for a long 
time to come. If inflation should really get a head of steam up, unemployment might rise to ten million or fifteen million. (Minutes, $8 / 19 / 58$, p. 57)

The chief economist to the Board of Governors was even more direct in seeing a link between overexpansion and downturn. He said:

Increasing demands after mid-1955 resulted in relatively small increases in output but marked advances in prices .... Distortions such as undue inventory accumulation, too hasty capital expansion in some areas, too rapid a rise in debt burden, and consumer resistance to price increases undermined the prevailing high activity and led to the recession of 1957-58. (Minutes, 9/22/59, p. 8)

Fiscal policymakers expressed a similar view. The 1956 Economic Report stated:

As a Nation, we are committed to the principle that our economy of free and competitive enterprise must continue to grow. But we do not wish to realize this objective at the price of inflation, which not only creates inequities, but is likely, sooner or later, to be followed by depression. (EROP, 1956, p. 28)

The 1958 Economic Report stated: "we must be continuously on guard against resort to measures that might provide a spurt in activity at the cost of impairing the long-run health of the economy" (EROP, 1958, p. 3). The 1959 Economic Report provided a discussion of the mechanisms by which inflation hurt economic growth. It stated:

A persistent upward movement of prices would ... narrow markets at home for important groups of goods, lower our capability to compete in the world's markets, and by requiring restrictive fiscal and monetary policies, lessen our chances of fully realizing our potential for economic growth. (EROP, 1959, p. 48)

In addition to this firm belief that overexpansion would have detrimental effects, monetary policymakers in the 1950 s also had a relatively modern view of the process of disinflation. There was much discussion of inflationary expectations and the persistence of inflation, especially late in the decade. For example, in February 1959, one member of the FOMC spoke of the "rampant inflationary psychology" (Minutes, 2/10/59, p. 22). Also, there was a sense that tight policy and slack were necessary to reduce inflation. In 1958, Chairman Martin noted that "[h]e did not know how to deal with the specifics of the problem [of inflationary psychology] except by moving in the right direction within the System" (Minutes, 8/19/58, p. 59). In 1959, Martin was much more direct about the costs of disinflation. 
He said, "He hoped that inflation would not get out of hand to such an extent that a very serious price would have to be paid for its correction" (Minutes, $1 / 6 / 59$, p. 37).

\section{The 1960s}

There was a marked shift in policymakers' view of the economy in the 1960s. Policymakers in the 1960s adopted a highly optimistic view of the levels of output and employment that could be reached without triggering inflation. Also, in stark contrast to policymakers in the 1950 s, policymakers in the 1960s came to believe in a long-run tradeoff between unemployment and inflation.

The shift was clearest and sharpest among fiscal policymakers. The 1962 Economic Report of the President, the first under the Kennedy Administration, identified 4\% as a "reasonable and prudent" unemployment rate that aggregate demand policy should aim for given the structure of the economy (EROP, 1962, pp. 46, 48). This assessment did not change noticeably throughout the 1960 s. ${ }^{\text {G }}$ The 1962 Economic Report estimated that potential output was growing at an annual rate of 3.5\% (EROP, 1962, p. 113). This figure was gradually raised, and by 1967 the estimate was $4 \%$ (EROP, 1967, p. 44).

Fiscal policymakers in the 1960 s were sufficiently confident in their estimates of the sustainable rate of unemployment that they consistently attributed inflation that arose before unemployment reached this level to sources other than excess demand. In discussing the inflation of 1955-1957 - a period when unemployment averaged 4.3\% - the 1962 Economic Report argued that "[a] simple explanation running in terms of over-all excess demand is not satisfactory. If aggregate excess demand prevailed at all, it existed only briefly toward the end of 1955" (EROP, 1962, p. 171). The Report went on to blame the inflation on the concentration of the boom in durables and on union and corporate power (EROP, 1962, pp. 171-172, 175). The inflation of 1965 (when unemployment was 4.5\%) was attributed to idiosyncratic changes in food and commodity prices and was not expected to continue (EROP, 1966, pp. 65-67, 87-88).

The inflation of 1966 (when unemployment was 3.8\%) was ascribed to the economy approaching potential too fast, not to an excessive level of economic activity, and to idiosyncratic factors, and was 
again not expected to continue (EROP, 1967, pp. 72-73, 97-98). And in discussing the further rise in inflation in the second half of 1967 (when unemployment was 3.9\%), the Economic Report stated:

Demand was not yet pressing on productive capacity - over-all or in most major sectors. The period of slow expansion [from mid-1966 to mid-1967] had created enough slack so that production could respond to increasing demand without significant strain on productive resources. (EROP, 1968, p. 105)

Fiscal policymakers in the 1960s also came to believe that there was a long-run tradeoff between inflation and unemployment. In the early part of the decade, they felt that there was a large margin of slack in the economy, and so discussed the long run relatively little. Nevertheless, there were certainly hints that they perceived a long-run tradeoff (for example, EROP, 1962, pp. 46-47; 1963, p. 84; 1964, p. 117). Later in the decade, when they believed the economy was close to potential, policymakers expressed this view clearly. The 1967 Economic Report stated that "the economy is now in the range of trade-off between falling unemployment and rising prices," and that one must therefore ask: "how should we rank the advantages of fuller employment against the disadvantages of rising prices?" (EROP, 1967, p. 99). The 1969 Report began its discussion of inflation by presenting a scatter plot of inflation and unemployment over the years 1954-1968 and noting that "[i]t reveals a fairly close association of more rapid price increases with lower rates of unemployment" (EROP, 1969, p. 94). It then went on to say that "the choice of the ideal level of utilization is a social judgment that requires a balancing of national goals of high employment and reasonable price stability" (EROP, 1969, p. 62).

The views of monetary policymakers in the 1960s are somewhat harder to discern. It is clear that monetary policymakers, like the Administration, were very optimistic about the sustainable levels of output and employment. As described above, in the late 1950s normal, sustainable rates of unemployment were thought to be $5 \%$ or even higher. But in the early 1960 s, with unemployment between 5 and $6 \%$, there was general consensus that there was a wide margin of unutilized resources and that inflation was not a concern. In January 1963, for example, the Committee viewed a "significant reduction in the rate of unemployment" as desirable (PA, 1/29/63, p. 61). In May 1964, the Committee described the nominal GNP growth of $7.5 \%$ over the previous four quarters as "a moderate, sustainable 
pace" (RPA, 5/5/64, p. 84). And in 1968, when industrial production had been growing at an average annual rate of $7 \%$ over the past seven years, the Committee saw "relative slack" in capacity utilization, though not in the labor market (Minutes, 2/6/68, p. 36).

The narrative record does not provide explicit statements of a belief in a long-run tradeoff on the part of monetary policymakers in the 1960s. Indeed, in 1966 Chairman Martin continued to take the opposite position (Minutes, 1/11/66, p. 82). And monetary policymakers were quicker than their fiscal counterparts to attribute inflation to high levels of economic activity: beginning in late 1966, they often took the view that the economy was at or near capacity, and that this was leading to inflation. In December 1967, for example, they felt that "[i]t now appeared highly probable ... that upward pressures on prices would persist as the effects of higher costs were reinforced by those of rapidly expanding demands" (PA, 12/12/67, p. 199).

Crucially, however, monetary policymakers did not view the high levels of activity as unsustainable. The policy discussions and directives for the first half of 1968 provide considerable insight into their thinking. At the beginning of the year, unemployment was 3.7\%, and real GNP growth was expected to increase from its estimated pace of 4.4\% per year in the fourth quarter of 1967 (RPA, 2/6/68, p. 117). Yet policymakers' central concern was merely that inflation might continue, not that it would rise. A typical statement was that "prospects are for further rapid growth and persisting inflationary pressures" (for example, $\underline{\mathrm{RPA}}, 1 / 9 / 68$, p. 115), or that "unit labor costs would remain under upward pressure" (PA, 3/5/68, p. 123). Indeed, although monetary policymakers were less optimistic about inflation than the Council of Economic Advisers, they nonetheless expected inflation to fall (Minutes, 2/6/68, p. 45). In June, Congress enacted a tax surcharge, which the FOMC expected to slow real growth but not to lead to any significant decline in capacity utilization or rise in unemployment. Yet the Committee believed the surcharge would lead "to a gradual lessening of inflationary pressures" (RPA, 5/28/68, p. 154). It expected inflation to fall (PA, 6/18/68, p. 162; 7/16/68, p. 167), and it replaced the reference to "persisting inflationary pressures" in the policy directive with milder language about price 
increases (RPA, 7/16/68; p. 173). In short, although monetary policymakers did not spell out their worldview explicitly, it appears to have been consistent with fiscal policymakers'.

\section{The 1970s}

The narrative record suggests that there was another sea change in economic beliefs early in the 1970s. Both fiscal and monetary policymakers adopted the Friedman-Phelps natural-rate framework remarkably rapidly. Throughout the decade, policymakers believed that the change in inflation depended on the deviation of the unemployment rate from its normal level. However, the 1970s saw considerable swings in both the estimates of the natural rate and in views about the downward sensitivity of inflation to economic slack.

Early 1970s. The first evidence that policymakers adopted the natural-rate framework came in their view of what it would take to reduce inflation. The 1970 Economic Report (the first under the Nixon Administration) stated that "inflations have seldom ended without a temporary rise in unemployment" (EROP, 1970, p. 21), and that a policy of aggregate demand restraint

should ultimately produce high employment with much less inflation than we have recently experienced. During the transition, we may find both unemployment and inflation to be higher than would have been desirable if the inflation had not been allowed to persist so long. This is the price we must pay for having long pursued inflationary policies. Once inflation has been set in motion, there is no way of correcting it without some costs. (EROP, 1970, p. 22)

The Report went on to say that "a GNP gap places a downward pressure on the rate of inflation" (EROP, 1970, p. 58), and that policymakers expected that at the end of the year

output will be below its potential and the rate of inflation, while declining, will probably still be too high. The transition to an economy growing along the path of potential output at full employment with reasonable price stability will not have been completed. (EROP, 1970, p. 65)

This view that the change in inflation depends on the deviation of unemployment from the natural rate is the centerpiece of standard formulations of the natural-rate hypothesis. The obvious corollary to the view that inflation falls when unemployment is above its normal level is that inflation rises when unemployment is below its normal level. This view presents a striking contrast to that of just one 
Economic Report before. The 1969 Report had stated that the level of inflation depended on the unemployment rate and that a society could choose from the feasible combinations of inflation and unemployment. The 1970 Economic Report suggested instead that there was a long-run vertical Phillips curve and that society could have any inflation rate it wanted at the natural rate of unemployment.

The acceptance of the natural rate framework at the Federal Reserve appeared principally in the form of a new emphasis on expectations. Expected inflation plays a crucial role in the natural-rate framework: inflation differs from its expected value when employment is different from the natural rate. And, expected inflation, which had been virtually absent from policymakers' discussions during most of the 1960 s, suddenly began to play a key role in policymaking at the end of 1968 . In December, the FOMC felt that "[e]xpectations of continued inflationary pressures appeared to be widespread," and the Committee referred to "the persistence of inflationary pressures and expectations" and "the prevailing inflationary psychology" (PA, 12/17/68, pp. 219, 224; see also Minutes, 12/17/68, passim). This suggests that monetary policymakers no longer believed that inflation simply depended on the unemployment rate, but also on past behavior and other determinants of expectations.

While policymakers quickly adopted the natural-rate framework, their views about the level of the natural rate and the sensitivity of the change in inflation to deviations from the natural rate were initially very optimistic. The 1970 Economic Report estimated the natural rate of unemployment at 3.8\% and the growth rate of potential output at $4.3 \%$ per year (EROP, 1970, pp. 79, 81). And, it projected that an average shortfall of output from potential of about $2 \%$ over a 3 -year period would bring inflation down by about 3 percentage points (EROP, 1970, pp. 66, 84-85). Monetary policymakers were similarly optimistic. For example, in early 1970, with the unemployment rate around 4\% and only a very mild recession expected, policymakers expected inflation to begin falling by the end of the year ( $\underline{\mathrm{RPA}}, 2 / 10 / 70$, p. 99; 3/10/70, p. 106). In March 1971, the FOMC was interested in what type of stimulus would be needed to bring unemployment down to $4 \%$ by the end of 1972 , and the staff reported that this could be done with a considerable fall in inflation (Minutes, 3/9/71, pp. 33-35). 
When inflation failed to fall as quickly as policymakers had hoped, however, they responded by becoming dramatically more pessimistic about the downward responsiveness of inflation to slack. The 1972 Report raised the possibility of

[a] tendency to an unsatisfactorily high rate of inflation which persists over a long period of time and is impervious to variations in the rate of unemployment, so that the tendency cannot be eradicated by any feasible acceptance of unemployment. (EROP, 1972, p. 113)

At the Federal Reserve, Chairman Arthur Burns was sympathetic to this new, pessimistic view of inflation from the beginning of his term in February 1970. The Minutes of the June 8, 1971 meeting report that in Burns's judgment,

the old rules were no longer working. ... Years ago, when business activity turned down, prices would respond - with some lag — not by rising more slowly but by declining; and wages would follow. That kind of response had become progressively weaker after World War I, and of late one found that at a time when unemployment was increasing prices continued to advance at an undiminished pace and wages rose at an increasing pace. ... Time and again economists had hoped that the old business cycle would reassert itself in the sphere of prices and wages .... However, he had now come to the conclusion that the response had changed. (Minutes, 6/8/71, p. 50)

Burns went on to suggest that the rise of public sector unions, the impact of that rise on the labor movement in general, welfare, and other factors might be responsible for the change (Minutes, 6/8/71, $\mathrm{p}$.

51). He concluded that:

monetary policy could do very little to arrest an inflation that rested so heavily on wagecost pressures. In his judgment a much higher rate of unemployment produced by monetary policy would not moderate such pressures appreciably. (Minutes, 6/8/71, p. 51)

Such views were common at the Federal Reserve in this period (for example, Minutes, 1/12/71, p. 25; 5/11/71, pp. 28-29; 6/29/71, pp. 34-35).

Mid-1970s. In the middle part of the 1970s, policymakers gradually reverted to more conventional views of the dynamics of inflation. The 1974 Economic Report, for example, although warning that the course of reducing inflation would be "long and difficult," painted a standard picture of the impact of aggregate demand restraint on inflation (EROP, 1974, pp. 21-23, 27-28). Similarly, the 1975 Economic Report said that "a shift to policies of restraint first exerts an adverse influence on output and the desired price deceleration effect materializes only with a lag" (EROP, 1975, pp. 128-129). The 
1977 Economic Report stated: "Nor can one deny that a slack economy with low utilization of capital and labor resources is usually a moderating influence on prices and wages" (EROP, 1977, p. 57). The

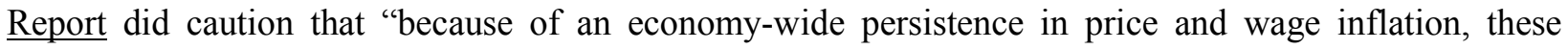
excess demand and excess supply effects sometimes seem to work very slowly, with their influence spread over a long period" (EROP, 1977, p. 57). But these persistence effects were thought to be symmetric. On the monetary side, policymakers concluded at the same time that the appropriate antidote to inflation was conventional monetary tightening. And in March 1977, one member of the FOMC "noted that the substantial margin of unused capacity and the high rate of unemployment at this time should tend to limit the rate of increase in wage rates and in the broad measures of prices" (RPA, 3/15/77, pp. 198-199).

Similarly, policymakers' views concerning sustainable output and unemployment became steadily less optimistic over the early and mid-1970s. In 1971, fiscal policymakers suggested that the natural rate of unemployment might be $4 \%$ or somewhat higher (EROP, 1971, pp. 76-78); in 1972, they calculated that demographic changes might have added one-half percentage point to the natural rate relative to the 1950s (EROP, 1972, pp. 113-116); and in 1974, they argued that the economy might have been at potential in 1973, when unemployment averaged $4.9 \%$, and that the growth rate of potential output might be below 4\% per year (EROP, 1974, pp. 58-65). The views of monetary policymakers underwent a similar evolution. For example, the Minutes for June 1972 report:

As to the method of measuring potential output, [Chairman Burns] noted that the calculations the staff had presented ... were based on the assumption of a 3.8 per cent rate of unemployment. It was desirable for the Committee to have such calculations, since they were widely employed elsewhere. At the same time, it would be useful also to have supplementary calculations based on a more realistic unemployment rate-perhaps 4.5 per cent. (Minutes, 6/19-20/72, pp. 80-81)

This trend toward a higher estimate of the natural rate reached a peak in early 1977 . The Council of Economic Advisers devoted a substantial portion of the final Ford Administration Economic Report to discussing the natural-rate framework and providing new lower estimates of potential output and higher estimates of "full-employment" unemployment. The definition of the full-employment rate of 
unemployment given in the 1977 Report is textbook-perfect-“"the lowest rate of unemployment attainable, under the existing institutional structure, that will not result in accelerated inflation" (EROP, 1977, p. 48). The Report went on to say that the CEA of the 1960 s selected $4 \%$ for this measure, but that the 1977 CEA thought it was substantially higher. The CEA estimated that accounting for straightforward demographic changes raised this number to $4.9 \%$. And, if other changes more difficult to quantify were taken into account, "it is likely that they have raised the full-employment unemployment rate even higher than the current estimate, perhaps closer to 51/2 percent" (EROP, 1977, p. 51).

The records of the Federal Reserve make it clear that their estimate of the natural rate had also risen substantially by 1977 . In July:

concern was expressed that the lag in growth of productive facilities so far in this business expansion might result in the development of pressure against available capacity while the unemployment rate was still relatively high. (RPA, 7/19/77, p. 249)

In September, it was suggested that the estimated unemployment rate of $7.1 \%$ "was still significantly above the level that might be regarded as 'full employment,' even if that level were judged for structural reasons to be considerably higher than in the past" (PA, 9/20/77, p. 276). And then in December, when the most recent unemployment rate was estimated to be $6.9 \%$ :

one member questioned whether the over-all rate might not be about as low as could be expected, given the rapid growth in the labor force. He suggested that the high rate of unemployment was a structural problem that could not be solved with monetary policy instruments. ( $\underline{\text { RPA }}, 12 / 19-20 / 77$, p. 319)

In the mid-1970s, supply shocks were also incorporated into policymakers' model of the economy. The 1975 Economic Report, for example, had a cogent discussion of how an oil price rise could both depress output and lead to inflation (EROP, 1975, pp. 73-75, 190-192). Similarly, from the very start of the 1973 oil embargo, the FOMC believed that "[a] further weakening in activity and an appreciable rise in prices are in prospect because of the curtailment in oil supplies" (RPA, 12/17-18/73, p. 220). However, throughout the mid-1970s, supply shocks were not given a central role. For example, the 1975 Economic Report argued that supply shocks were not the key source of inflation in the early and mid-1970s. It stated: 
Supply reductions also contributed to imbalances between aggregate supply and demand, particularly in the past few years: crop failures and reduced oil supplies are the most notable examples. Without neglecting specific features, the U.S. inflation since the mid1960 's can nevertheless be analyzed in terms of a general conception of the inflationary process that emphasizes the role of monetary and fiscal policies. (EROP, 1975, p. 128)

Likewise, while the FOMC mentioned food and energy prices periodically, such shocks were typically mentioned as an aside rather than as a key determinant of macroeconomic conditions (see, for example, RPA, 8/20/74, pp. 193-194; 1/17-18/77, p. 167).

Late 1970s. In the late 1970s, the trends toward a more realistic model were reversed somewhat. First, estimates of the natural rate were reduced, at least among some policymakers. This change was most noticeable in President Carter's signed section of the 1978 Economic Report. It stated that: "Over the next several years I believe we can increase our real output by $4 \frac{1}{2}$ to 5 percent per year, and reduce unemployment by about one-half of a percentage point each year" (EROP, 1978, p. 5). Given that the unemployment rate at the time was $7.1 \%$, the belief that such sustained reductions in unemployment were possible suggests either that the President's estimate of the natural rate was quite low, or that he did not accept the natural rate framework at all.

The CEA's analysis in the 1978 and 1979 Economic Reports shows much less of a change. The Council's section of the 1978 Economic Report certainly endorsed the Friedman-Phelps framework and devoted an entire chapter to discussing the natural rate and its implications for policy. Of the 1977 revision of potential GNP and high-unemployment unemployment, the 1978 Report stated: "The present Council has reviewed the new estimates and concluded that they are a major improvement" (EROP, 1978, p. 83). It is true that while the 1977 Report emphasized that the new estimates were still surely too optimistic, the 1978 Report treated $4.8 \%$ as a plausible estimate of the natural rate (EROP, 1978, p. 84). But the 1978 CEA did discuss the possibility that "the overall unemployment rate at which inflation is likely to accelerate has risen by $1 \frac{1}{2}$ percentage points rather than 1 percentage point over the past 20 years" (EROP, 1978, p. 171). And, the 1979 Report concluded that "under current labor market conditions the danger of accelerating wages begins to mount as the rate of unemployment falls significantly below 6 percent" (EROP, 1979, p. 65). 
The prevailing estimate of the natural rate appears to have fallen at the Federal Reserve during 1978 and 1979. G. William Miller was appointed Federal Reserve chairman in March 1978. Over the next year and a half, there were numerous debates within the FOMC about the level of the natural rate. For example in April 1978, with the unemployment rate slightly above 6\%, two members suggested that the unemployment rate was approaching the level where unused labor resources of many kinds might be limited. A third member expressed disagreement with that view of the unemployment situation [and] ... suggested that it was not widely held. (PAA, 4/18/78, p. 162)

This optimistic view of the natural rate was reiterated by another member, who felt that "slack still existed in the utilization of industrial capacity and of the labor force" (RPA, 4/18/78, p. 162). There was a similar discussion in March 1979. With unemployment slightly below 6\%, some members expected a "significant easing from the rapid rise [of prices] of recent months" because "recent increases in prices represented temporary [supply] factors" (PA, 3/20/79, p. 139). That this more optimistic view of the natural rate carried the day is evidenced by the fact that at this meeting four members dissented because they felt that there were "strong inflationary forces reinforced by pressure on capacity in some industries" (

Policymakers in the late 1970s also put more emphasis on supply shocks than they had in the middle years of the decade. For example, in May 1978, several members of the FOMC "expressed the view that the rise [in inflation] was likely to be more rapid than projected by the staff" because "the supply-related increase in prices of foods over the remainder of 1978 would exceed the staff projection" (RPA, 5/16/78, pp. 175-176). Similarly, in early 1979, the rise in oil prices and the resulting general inflation led many members of the FOMC to feel that the probability of a recession had increased (RPA, 3/20/78, p.138). At the Council of Economic Advisers, supply shocks were given a substantial role in explaining recent macroeconomic developments. The 1978 Economic Report, for example, said that fluctuations in consumer prices in the period 1975 to 1977 "were principally due to erratic variations in food and energy prices" (EROP, 1978, p. 142). Perhaps more importantly, whereas the 1975 Economic Report emphasized the role of excess demand in causing the inflation of the early and mid-1970s, both the 
1978 and 1979 Economic Reports took the position that "the dominant influence was the rise in fuel and food prices" (EROP, 1978, p. 141; see also, EROP, 1979, pp. 38, 55).

An even more important change in beliefs in the late 1970s was the resurgence of Arthur Burns's view that slack had little impact on inflation. The President's section of the 1978 Economic Report stated:

Recent experience has demonstrated that inflation we have inherited from the past cannot be cured by policies that slow growth and keep unemployment high. ... The human tragedy and waste of resources associated with policies of slow growth are intolerable, and the impact of such policies on the current inflation is very small. ... Economic stagnation is not the answer to inflation. (EROP, 1978, p. 17)

In reviewing the inflation experience of the previous 10 years, the Report said:

The inflation would not have persisted during the 1970 recession if wages and prices were very sensitive to economic slack. On the basis of the experience of that period, and the similar one more recently, estimates of the size and duration of the demand restraint and output loss that it takes to slow inflation have been revised sharply upward. (EROP, 1978, p. 140)

There was an extended discussion that "some longer-term decrease in downward flexibility, especially of wages, seems evident" (EROP, 1978, p. 145). The Council concluded that "an attempt to purge inflation from the system by sharp restrictions on demand would require a long period of very high unemployment and low utilization of capacity" (EROP, 1978, p. 150). Similarly, the 1979 Report stated: "The stubborn resistance of inflation to the traditional remedies reflects the fact that the rate of wage and price increase is relatively inflexible in the face of slack demand," and that "[r]eductions in output and major increases in unemployment are no longer as effective in slowing the rate of wage and price increase" (EROP, 1979, p. 78).

The FOMC under Chairman Miller also showed some of the increased pessimism about the ability of tight policy to reduce inflation evident in the early Carter Administration Economic Reports. For example, in August 1978:

One negative element in this pattern, which seriously concerned all members of the Committee, was the unexpectedly high recent rate of inflation in prices and wages and the related possibility that an appreciable slowing of inflation would prove more difficult to achieve than previously had been anticipated. (ㄹA, $8 / 15 / 78$, p. 210) 
As late as May 1979 it was noted that:

There was evidence that over time the rate of inflation had been less variable in the United States than in other industrial countries, suggesting that it would be more difficult to reduce the rate here. According to a number of economic projections, moreover, deceleration of inflation would be a slow and lengthy process. (RPA, 5/22/79, pp. 161162)

\section{E. The 1980s and 1990s}

The Modern Consensus. The end of the 1970s and the beginning of the 1980s saw the emergence of an important new consensus among policymakers about the functioning of the economy and the effects of policy. The natural-rate hypothesis, with its rejection of a long-run tradeoff between unemployment and inflation, provided the guiding framework of the consensus. The first Economic

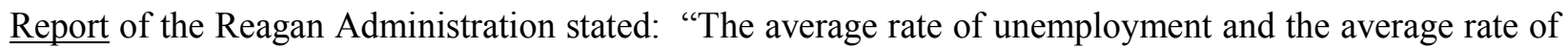
inflation are best regarded as unrelated in the long term" (EROP, 1982, p. 52). Or, as the 1983 Economic

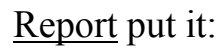

In the 1960s, many economists believed that the Federal Government could keep unemployment down permanently by accepting a higher rate of inflation. ... During the 1970s these views proved to be incorrect. (EROP, 1983, p. 18)

The Report went on to say:

Historical experience suggests that the change in the rate of inflation depends both on the rate at which economic activity is expanding and on the level of economic slack. If the slack in the economy declines too rapidly, or capacity utilization is held at too high a level, inflation will tend to increase. The lower limit on unemployment below which inflation will tend to increase is referred to as the inflation threshold unemployment rate. (EROP, 1983, p. 37, emphasis in the original)

The new consensus of beliefs had four critical elements beyond the central place of the naturalrate hypothesis. First, policymakers in the early 1980s had substantially higher estimates of sustainable unemployment than many of their predecessors over the previous two decades. The 1982 Economic $\underline{\text { Report }}$ argued that capacity constraints had caused inflation to rise in 1978-1979, a period when

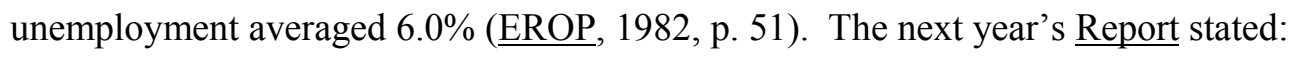

While it is not easy to pinpoint the inflation threshold unemployment rate precisely, it probably lies between 6 and 7 percent. Econometric studies of historical data suggest 
that when unemployment is close to 6 percent, the rate of inflation tends to accelerate. (EROP, 1983, p. 37)

Second, policymakers returned to the view that aggregate demand policies did provide a means of reducing inflation. The early Economic Reports of the Reagan Administration contained standard discussions of how in the short run, restrictive aggregate demand policies would push output below its sustainable level and unemployment above its natural rate, and bring about reductions in inflation. The 1982 Report stated, "policies designed to reduce inflation significantly will temporarily increase unemployment and reduce output growth" (EROP, 1982, p. 58; see also pp. 24-25, 47). Similarly, the 1983 Report stated,

the historical experience of the United States and other countries suggests that disinflation is generally associated with lost output and increased unemployment. During periods of disinflation and recession, the measures available to reduce the pain of the transition from accelerating inflation to price stability are limited. Greater fiscal or monetary stimulus might increase employment, but only at the risk of igniting inflation. (EROP, 1983, p. 37)

Monetary policymakers shared these views that economic slack would tend to bring about reductions in inflation, but that unemployment above the range of 6 to $7 \%$ was needed to do so. For example, in March 1980, when the unemployment rate was in the vicinity of $6 \%$, FOMC members felt that "the underlying inflation rate would not be reduced very much in the short run by the rather moderate contraction in activity generally being projected" (PA, 3/18/80, p. 108). In July 1981, when unemployment was slightly over $7 \%$,

[w]hile expecting the rate of inflation to remain high by historical standards, nearly all members anticipated some improvement. A number ... felt that significant and sustained progress in reducing the underlying rate of inflation would take time and might not be consistent with an early and strong rebound in economic activity. (RPA, 7/6-7/81, p. 116)

And in October 1982, with unemployment in the vicinity of $10 \%$, the Committee felt that

further moderation in labor cost and price pressures and also in inflationary expectations was a reasonable anticipation, given an environment of moderate expansion in output and employment, relatively low levels of resource utilization, and prospects for improvements in productivity. ( $\underline{\mathrm{RPA}}, 10 / 5 / 82$, p. 124) 
Indeed, at virtually every meeting in this period, the staff and members expected gradual declines in underlying inflation as the result of economic slack.

The third important element of the new consensus was agreement that means other aggregate demand policies were not viable cures for inflation. Much of the evidence of this shift comes from what is not in the policy record: after the presentation of a proposal for tax-based incomes policies in the final Economic Report of the Carter Administration (EROP, 1981, pp. 14, 57-68), discussion of wage and price controls, guideposts, incomes policies, and voluntary wage and price cooperation virtually disappeared from the narrative record of stabilization policy. But there is also some direct evidence of this shift in beliefs. For example, the 1982 Economic Report stated, "Neither guideposts nor price controls ... have succeeded in stopping inflation" (EROP, 1982, p. 49).

The final element of the consensus was agreement that the costs of inflation were substantial. The 1982 Economic Report referred to "the acute costs of rising inflation" (EROP, 1982, p. 47), and the 1983 Report stated:

Of all the economic problems that this Administration inherited when it came to office in 1981, the most urgent was the problem of rising prices. Double-digit inflation had created serious economic distortions. (EROP, 1983, p. 19)

Monetary policymakers appear to have had similar views. For example, in February 1980, "Committee members continued to express great concern about the inflationary environment and its role in generating distortions and instability" (로, 2/4-5/80, p. 101).

Another fundamental change that occurred in the 1980 s concerned the beliefs relevant to fiscal policy. In the first three decades of the postwar era, the aggregate demand implications of budget policy were seen as crucial. Starting with the beginning of the Reagan Administration, however, the impact of budget deficits on aggregate demand became of secondary importance. Instead, the key beliefs motivating fiscal policy concerned two long-run issues: the appropriate size of government, and the importance of the incentive effects of taxes relative to the government's direct impact on national saving. Since the beliefs underlying fiscal policy in the 1980s and 1990s no longer concerned the issues of 
aggregate demand management that are the focus of this paper, we do not review the evolution of those beliefs here.

Continuity and Change in the 1990s. The central features of policymakers' beliefs have undergone remarkably little change over the past twenty years. Monetary policymakers have remained passionate in their views of the harms of inflation. In 1997, for example, Federal Reserve Chairman Alan Greenspan stated:

the evidence is compelling that low inflation is necessary to the most favorable performance of the economy. Inflation, as is generally recognized throughout the world, destroys jobs and undermines productivity gains .... Low inflation is being increasingly viewed as a necessary condition for sustained growth. (Greenspan, 1997, p. 1)

A natural-rate framework has continued to be a core element of policymakers' beliefs in the

1990s. The first Economic Report of the Administration of George H. W. Bush referred to:

the widely accepted view that, when inflationary expectations are stable, the economy has a minimal rate of unemployment consistent with nonaccelerating inflation. The nonaccelerating inflation rate of unemployment, often referred to as the NAIRU or natural rate of unemployment, is an important guide for policymakers. (EROP, 1990, p. 177)

Similarly, the NAIRU featured prominently throughout the Economic Reports of the Clinton Administration (see, for example, EROP, 1994, pp. 109-112; 2001, pp. 73-74). At the FOMC, policy discussions focused on the relation between actual output and the economy's normal capacity, and there was broad agreement that a situation where output persistently exceeded capacity was unsustainable because of its inflationary consequences. In February 2000, for example, the FOMC felt that

The economy's potential to produce goods and services had been accelerating over time, but the demand for output had been growing even more strongly. If this imbalance continued, inflationary pressures were likely to build that would interfere with the economy's performance. ( $\underline{\text { RPA }}, 2 / 1-2 / 2000$, p. 204)

During the decade, policymakers gradually raised their assessment of the path of potential output.

There was considerable uncertainty and some divergence of views both about the magnitude of the change and about its implications for the natural rate of unemployment. Fiscal policymakers were the most cautious. They argued that it was difficult to know how long-lasting the increase in productivity 
growth would be, and that a reasonable estimate was that some of it was transitory (EROP, 2001, pp. 2829, 77). They also believed that:

The new, higher trend growth of productivity since 1995 has temporarily lowered the NAIRU (the nonaccelerating-inflation rate of unemployment ...), because it can take many years for firms and workers to recognize this favorable development and incorporate it into their wage setting. (EROP, 2001, p. 73)

Because of this belief that the increased productivity growth was temporarily reducing the natural rate, fiscal policymakers concluded that an unemployment rate in the vicinity of $4 \%$ was clearly below its sustainable long-run level (EROP, 2001, p. 74).

At least some monetary policymakers, on the other hand, felt that the changes in the 1990 s were more significant. For example, in June 1999 the Federal Reserve argued that "a further pickup in productivity growth is a distinct possibility" (Monetary Policy Report to the Congress, July 20, 2000; in Annual Report, 2000, p. 63). With regard to the labor market, there were clearly two distinct positions within the FOMC. Some members shared the CEA's view that the increase in productivity growth had merely lowered the natural rate temporarily. In June 2000, for example, with unemployment at $4.0 \%$, some members felt that "labor markets were already operating at levels of utilization that were likely eventually to produce rising labor costs ... even if productivity growth remained high or rose somewhat further" (PA, 6/27-28/2000, p. 232). Similarly, in August 2000, "a number of members" felt that "a flattening out of the rate of increase in productivity, even at a high level, could well pose at some point a

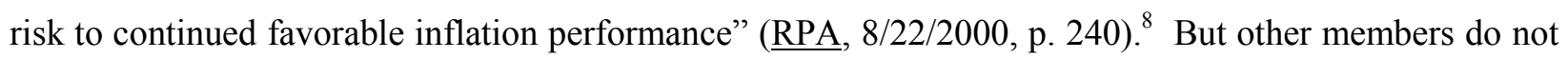
appear to have seen the changes in the labor market as temporary. At the meeting in June 2000 when some members thought prevailing labor market conditions were not sustainable, "[o]ther members were more optimistic .... To date, unit labor costs had been quite subdued, leaving open the question of what was a sustainable level of labor resource use" (PA, 6/27-28/2000, p. 232). And, in December 2000, there was considerable sentiment that recently prevailing patterns of the relation between labor utilization and inflation provided a good guide for the future (RPA, 12/19/2000, p. 264). 
A final change in beliefs in the 1980s and 1990s concerned the importance of acting to prevent inflation by moving preemptively. In the years immediately after its shift in operating procedures in October 1979, the Federal Reserve put considerable emphasis simply on bringing about a gradual reduction in money growth in order to ensure a gradual decline in inflation. But in the 1990s, monetary policymakers viewed their job as more subtle:

Too often in the past, policymakers responded late to unfolding economic developments and found they were behind the curve .... Those who wish for us ... to await clearly visible signs of emerging inflation before acting are recommending we return to a failed regime of monetary policy that cost jobs and living standards.

I wish it were otherwise, but there is no alternative to basing policy on what are, unavoidably, uncertain forecasts. (Greenspan, 1997, p. 2)

Despite these changes at the end of the century, the analysis of the narrative record for the postwar era fundamentally leaves one with the sense that policymakers' beliefs have almost come full circle. Both in the 1950s and in the 1980s and 1990s, the key features of policymakers' model of the economy were a realistic view of sustainable unemployment and a conviction that inflation was very costly. In between these two points, however, there was an extended detour in policymakers' beliefs toward very optimistic estimates of sustainable unemployment and deep pessimism about the ability of economic slack to reduce inflation.

\section{EVIDENCE OF CHANGES IN BELIEFS FROM FEDERAL RESERVE FORECASTS}

One way to see if the evolution of economic beliefs apparent in the narrative record is genuine and meaningful is to look at the Federal Reserve's internal forecasts. These forecasts provide a window into the model of the economy held by the staff of the Board of Governors. To the degree that the staff 's model reflects or influences the framework held by members of the Federal Open Market Committee, the forecasts can provide a window into the economic beliefs of the actual monetary policymakers. Unfortunately, a similarly regular and confidential forecast from the Council of Economic Advisers does not exist to provide insight into the thinking of fiscal policymakers. 


\section{A. The Greenbook Forecasts}

The Federal Reserve's staff forecast is contained in the "Greenbook" prepared before each meeting of the Federal Open Market Committee. These forecasts begin in November 1965 and are available to the public through December 1996. Because the forecasts begin in the mid-1960s, we can only use them to investigate changes in beliefs between the 1960s and today; we cannot use them to verify the large changes in beliefs between the 1950s and the 1960s apparent in the narrative record. The horizon of the forecasts has lengthened over time. In the late 1960s and early 1970s, the forecasts typically went out only 1 or 2 quarters; in the Volcker and Greenspan eras, they have typically gone out 6 to 8 quarters. Therefore, for consistency we can only look at changes in medium-term forecasts over time. While the staff forecasts a plethora of variables, we consider only the forecasts for the change in the GNP/GDP deflator and the unemployment rate.

There is no question that the staff forecasts play a crucial role in monetary policymaking. A reading of the Minutes and the Record of Policy Actions of the FOMC for different eras shows that the staff forecasts are typically the starting point for discussions of policy. While individual members of the FOMC may express disagreement with the forecast, it is rare that the majority of the Board challenges it or disregards it. Much more often, the FOMC chooses policy on the basis of how it wants inflation and real output growth to move relative to the forecast. Therefore, it is plausible that the model implicit in the forecasts reflects, or is at least not wildly at odds with, the model held by the majority of the FOMC.

\section{B. Forecast Errors for Inflation}

We first analyze the forecast errors for inflation. Economic beliefs are likely to be reflected in the overall accuracy of the forecasts. A more realistic model, all else equal, is likely to produce smaller forecast errors. More importantly, beliefs are likely to affect the bias of the forecasts. For example, if the forecasts in a period were based on an overly optimistic view of the natural rate or of the ease of reducing inflation, they would tend to systematically underpredict inflation. The same would be true if the forecasts were based on a belief in a long-run tradeoff and unemployment was below the natural rate. 
Method. To calculate forecast errors for inflation, one obviously needs a series for comparison. We use a nearly real-time, unrevised version of the NIPA data on the GNP/GDP deflator. In particular, we use the "final" revision for each quarter, which is typically available at the end of the subsequent quarter. ${ }^{\square}$ This series represents the most accurate measure of actual GNP/GDP inflation available near the time the forecasts were made. As such, it is a plausible goal toward which the Federal Reserve forecasters could have been aiming.

The forecast data are by FOMC meeting. In the early part of the sample there were FOMC meetings virtually every month, and occasionally two in one month. In the later period there were typically eight meetings per year. We calculate the forecast errors corresponding to each forecast. The errors are then assigned to the months in which the forecasts were made. If there are two forecasts in a month for which data are available, the forecast errors are averaged to yield a single monthly value.

We calculate forecast errors for all horizons up to three quarters ahead. (For horizons farther ahead, there are so few observations in the 1960s and the early 1970s that comparisons over time are meaningless.) We choose as our baseline case the average inflation forecast error for the horizons 0,1 , and 2 quarters ahead. This average looks at the accuracy of the Federal Reserve forecasts over a mix of short-term and medium-term horizons. However, the results are very similar for other averages and for each horizon separately.

Results. The average Federal Reserve forecast errors for 0 to 2 quarters ahead are graphed in Figure 1.10 Summary statistics for this series are given in Table 1 . The sample periods underlying the summary statistics correspond to both the tenure of individual Federal Reserve chairmen and to interesting groupings of chairmen. Because the forecasts change dramatically part way through the Burns era, a single summary statistic for this period would be misleading. For this reason, we analyze both an early and a late Burns sample period.

The most obvious characteristic is that the forecast errors have declined over time. The root mean squared error was 1.7 percentage points in the period 1967:10 to 1979:7, 0.8 in the Volcker years 
(1979:8 to $1987: 7)$, and 0.5 in the Greenspan years (1987:8 to 1996:12). Figure 1 shows that errors were declining in the mid-1970s, but then surged again in 1978 and 1979.

Another obvious characteristic is that there has been a fundamental change in the bias of the forecasts. In the late 1960s and early 1970s, the average forecast error (calculated as actual inflation minus the forecasted value) was substantially positive. That is, the Greenbook forecasts substantially underpredicted inflation in this period. The mean error was 1.2 percentage points in the late Martin and early Burns period (1967:10 to 1975:6). In both the Volcker and Greenspan eras, the average forecast error was small and slightly negative ( -0.4 percentage points and -0.3 percentage points, respectively). Thus, in contrast to the forecasts for the 1960s and 1970s, the modern Greenbook forecasts have, if anything, tended to overpredict inflation.

The bias in the forecasts exhibits interesting fluctuations in the 1970s. The forecasts became dramatically less positively biased in the middle of the decade. Between 1975:7 and the end of Arthur Burns's tenure as chairman in 1978:2, the mean error was -0.2 percentage points. Then during the Miller era (1978:3 to $1979: 7)$, the mean error rose to 0.9 percentage points. Because the period when the forecasts display little bias is quite brief, it is difficult to know whether it reflects temporary good luck or genuine improvement in understanding of the economy. Likewise, the surge under Miller could reflect either bad luck or knowledge regress. The declines in bias under Volcker and Greenspan are protracted enough that they are unlikely to represent temporary forecasting luck.

Both the improvement in overall forecast accuracy and the reduction in bias are consistent with the changes in economic beliefs that we observe in the narrative record. The belief in a permanent tradeoff between unemployment and inflation and very low estimates of normal unemployment that characterized the economic beliefs of policymakers in the 1960s and 1970s would naturally tend to lead policymakers to systematically underpredict inflation.11 As policymakers came to understand the absence of a permanent tradeoff and raised their estimates of normal unemployment in the 1980s and 1990s, it is natural that their forecasts became more accurate and less systematically overoptimistic. 


\section{Implicit Estimates of the Natural Rate of Unemployment}

Because the Greenbooks contain forecasts of both real variables and inflation, they can shed light on the Federal Reserve's implicit views about the relationship between real activity and inflation. For example, forecasts based on highly optimistic views of sustainable output and unemployment, or on the belief that inflation is naturally transitory, will tend to predict declining inflation in the face of high economic activity.

To summarize the view of the relationship between the real economy and inflation implied by the forecasts, we compute "implicit" or "shadow" estimates of the natural rate of unemployment. That is, we ask what estimate of the natural rate is consistent with the forecasts for inflation and unemployment, under the assumption that the change in inflation depends in a conventional way on the departure of unemployment from its natural rate. Obviously, the forecasts were not always made using this framework: often policymakers did not have a natural-rate framework at all, or had unconventional views of how inflation responds to unemployment. Nonetheless, changes in forecasters' economic beliefs are likely to be reflected in changes in these computed natural rates of unemployment. That is, we interpret the calculated natural rates not as estimates of the natural rates that forecasters were actually using at various times, but simply as convenient summaries of the views of the unemployment-inflation relationship underlying the forecasts.

Method. The calculation of the natural rate implied by the forecasts is straightforward. We use the standard rule of thumb that an unemployment rate one percentage point above the natural rate for a year reduces the rate of inflation (measured using the GNP/GDP deflator) by one half of a percentage point. 12 That is:

$$
\Delta \pi_{\mathrm{t}}=0.5\left(\mathrm{u}_{\mathrm{t}}-\overline{\mathrm{u}}_{\mathrm{t}}\right)
$$

where $\pi$ is inflation over a year, $\mathrm{u}$ is the annual unemployment rate, and $\overline{\mathrm{u}}$ is the natural rate. 
To back out the implied estimate of the natural rate, we simply take the forecasted change in the rate of inflation over some horizon and the predicted average unemployment rate over the same horizon and this assumed sensitivity. The implicit natural rate is the rate that makes the two forecasts consistent given the assumed sensitivity. We consider a variety of horizons. The one that we focus on is the change in the rate of inflation from the quarter before the forecast to two quarters after. This is comparable to the baseline case that we examine for the forecast errors. This three-quarter horizon includes at least a medium-term forecast, but does not cause us to lose too many observations early in the sample. As with the analysis of forecast errors, the results for the implicit natural rate are robust to considering different horizons.

Equation (1) implies that with quarterly data, $\Delta \pi_{t}=1 / 8\left(u_{t}-\bar{u}_{t}\right)$. If the forecast is based on the assumption of a constant natural rate over the three-quarter horizon, this implies $\Delta \pi_{\mathrm{t}}+\Delta \pi_{\mathrm{t}+1}+\Delta \pi_{\mathrm{t}+2}=$ $1 / 8\left(u_{t}-\bar{u}_{t}\right)+1 / 8\left(u_{t+1}-\bar{u}_{t}\right)+1 / 8\left(u_{t+2}-\bar{u}_{t}\right)$. We calculate the implied natural rate in the forecast by solving this expression for $\overline{\mathrm{u}}_{\mathrm{t}}$ :

$$
\overline{\mathrm{u}}_{\mathrm{t}}=1 / 3 \sum_{\mathrm{i}=0}^{2} \mathrm{u}_{\mathrm{t}+\mathrm{i}}+{ }^{8} / 3\left(\pi_{\mathrm{t}+2}-\pi_{\mathrm{t}-1}\right)
$$

This implied natural rate is calculated for each Greenbook forecast. We then convert the results to a monthly series by assigning the implied natural rate to the month in which the forecast occurred. For the few months when two forecasts were conducted, we calculate the monthly value by averaging the two observations.

Results. Figure 2 graphs the implied natural rates for 1967:10 to $1996: 12.13$ The series is clearly quite variable even in recent years. This presumably reflects the fact that the Federal Reserve staff has other information about likely influences on inflation, such as supply shocks. Because our simple calculation assumes that the only determinant of changes in inflation is the departure of unemployment from the natural rate, the inclusion of these other influences in the forecasts of inflation reveals itself as gyrations in our implicit natural rate series. 
The much more important finding apparent in Figure 2 is that the implicit estimates of the natural rate were much lower in the late 1960s and early 1970s than in the Volcker and Greenspan eras. Table 2 gives the summary statistics for the implied estimates of the natural rate for different eras. The average implied estimate for 1967:10 to 1975:6 is just 2.9\%, while for the Volcker and Greenspan years (1979:8 to $1996: 12$ ) it is $7.3 \%$. That is, fitting the forecasts for the 1960 s and early 1970 s into a natural-rate framework requires using an extremely low estimate of the natural rate. This finding is consistent with the narrative evidence suggesting that policymakers in this era believed either in a permanent tradeoff between inflation and unemployment, or were highly optimistic in their estimates of achievable long-term unemployment. The forecasts for the Volcker and Greenspan periods, in contrast, are quite consistent with a natural-rate framework with a reasonable (though slightly high) estimate of the natural rate. Again, this is precisely what the narrative evidence suggests should be the case.

As with the forecast errors, the implicit estimates of the natural rate in the mid- and late 1970s show interesting variation. The implicit estimates were remarkably high in the late Burns era (1975:7 to

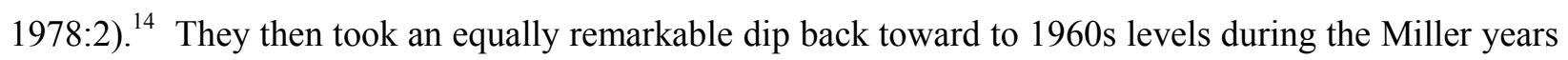
(1978:3 to 1979:7). This latter finding is consistent with the narrative evidence that at least some members of the FOMC during the Miller years were unrealistic in their estimates of the natural rate.

\section{NARRATIVE EVIDENCE ON THE RELATIONSHIP BETWEEN POLICYMAKERS' BELIEFS AND POSTWAR STABILIZATION POLICY}

The previous two sections have shown that the framework policymakers used to understand the economy evolved over time. What remains to be done is to show that this evolution of beliefs was reflected in the policy choices that were made in different eras. One way to do this is to again consider narrative evidence. Do the records of the Federal Reserve and the Council of Economic Advisers suggest that key policy decisions were motivated by policymakers' model of the economy? 


\section{A. Measures of Policy}

Before one can see if policy changes were motivated by beliefs, one needs to know what policy actions were taken in various eras. To this end, we consider two standard measures of aggregate demand policy. The stance of fiscal policy is well summarized by the ratio of the high-employment surplus to potential GDP. The high-employment surplus shows what the Federal budget stance would be if GDP were at potential. Normalizing by potential GDP removes the trend caused by growth in the economy over time. We use quarterly data on the high-employment surplus and potential GDP from 1950 to the present from the Congressional Budget Office. 15 The high-employment surplus to GDP ratio is graphed in Figure 3.

An appropriate summary statistic for monetary policy is more controversial. We use an estimate of the real federal funds rate as our measure. At various points in its history the Federal Reserve has targeted different indicators — free reserves in the 1950s, non-borrowed reserves and monetary aggregates in the late 1970s and early 1980s, the federal funds rate in the mid-1970s and the late 1980s and the 1990s. But in all eras, some short-term interest rate was at least a supplementary target. More fundamentally, a short-term interest rate is a consistently good indicator of money market conditions in virtually all eras. Since the funds rate is the most commonly targeted short-term rate, we choose that as our indicator 16

Because inflation has varied so substantially over time, we construct an estimate of the ex ante real federal funds rate. To do this, we calculate the ex post real rate using the GDP deflator to measure inflation. We then use a Mishkin (1981) procedure to estimate the ex ante real rate. In particular, we regress the ex post real rate on a constant, a trend, and four lags of each of the nominal funds rate, the deviation of $\log$ output from trend, and inflation. 17 The fitted values of this regression are our estimates of the ex ante real funds rate. This series is graphed in Figure 4.

The next step in the analysis is to examine whether key movements in these policy indicators were motivated by policymakers' beliefs about how the economy worked. In this analysis we consider 
the same sources as before - the Economic Report of the President and the Minutes, Transcripts, and Record of Policy Actions of the Federal Open Market Committee.

\section{B. The 1950s}

An Early Commitment to Aggregate Demand Management. The first thing to notice about the policy indicators in the 1950s is that they moved around substantially in response to macroeconomic conditions. For example, when inflation began to rise in late 1954 and 1955, both the high-employment surplus and the real federal funds rate rose. Similarly, in the 1957-1958 recession, both indicators declined substantially, indicating a switch to expansionary policy. This is important because there is a tendency to think that aggregate demand policy only started to be used in the 1960 s and that policymakers in the 1950s did not feel a responsibility for managing the economy. But the narrative and empirical records show that the commitment to activist aggregate demand management was already in place in the early 1950s. Thus, the fundamental shift in attitudes about the role of government in managing the economy occurred at or before the start of the postwar era.

The narrative evidence that both fiscal and monetary policymakers felt a commitment to real output stabilization in the 1950s is substantial. The 1956 Economic Report of the President, for example, stated: "we have also come to believe that progress need not proceed as irregularly as in the past, and that the Federal Government has the capacity to moderate economic fluctuations" (EROP, 1956, p. iii). It also referred to "a responsibility on the Government to pursue policies that will help to keep the private economy strong and growing" by "acting promptly and resolutely when either recessionary or inflationary influences in the general economy become evident" (EROP, 1956, p. 8). The Federal Reserve clearly felt a similar, if somewhat less strong, responsibility toward real stability. For example, at the start of the 1953-1954 recession, the Federal Reserve adopted a program of "active ease" in September 1953 (Minutes, 9/8/53, p. 12), and had as the primary goal of monetary policy "avoiding deflationary tendencies" (Minutes, 9/24/53, p. 29). 
As the reference above to avoiding both "recessionary or inflationary influences" makes clear, policymakers in the 1950 s also felt a responsibility to maintain price stability. The 1958 Economic Report stated: “A clear responsibility rests on Government to pursue policies that will help prevent inflation" (EROP, 1958, p. 4). Earlier, the 1956 Economic Report recounted that:

the unfolding of prosperity generated a degree of exuberance which, if left to itself, could have led to widespread increases in prices, speculative buying, new price increases, and eventual economic recession. The Federal Government, keenly aware of its responsibilities under the Employment Act, moved resolutely to prevent such developments. (EROP, 1956, p. 28)

The 1959 Economic Report discussed the Eisenhower Administration's proposal "to amend the Employment Act of 1946 to make reasonable price stability an explicit goal of Federal economic policy" (EROP, 1959, p. vi).

Such a feeling of responsibility toward inflation control was, if anything, more evident at the Federal Reserve. For example, when industrial prices started to rise in the summer of 1955, Chairman Martin said, "Inflation is a thief in the night and if we don't act promptly and decisively we will always be behind" (Minutes, 8/2/55, p. 13). Again in 1958 when the FOMC feared inflation was about to rise again, one governor said that "the country was going to have inflation and that there must be serious shock treatment" (Minutes, 9/9/58, p. 27). Perhaps the most telling statement of what the Federal Reserve took to be its responsibilities in this era was made in 1959. One member of the FOMC expressed the view that: "The System, of course, wanted growth as well as [price] stability, but if temporarily there had to be a choice between growth and arresting inflationary psychology he would favor the latter course" (Minutes, 2/10/59, p. 22).

This sense of responsibility toward managing the economy is particularly evident if one looks at the Record of Policy Actions of the FOMC during the 1950s. Far from being unconcerned or unresponsive to economic conditions, the FOMC frequently changed what it said it was trying to accomplish in response to economic conditions. Consider, for example, the fairly typical year of 1956. The FOMC met 19 times during the year. The policy directive given to the open market manager was changed at five of those meetings. For example, in January, "there had been a slight - perhaps almost 
imperceptible - change in the state of the economy" (RPA, 1/24/56, p. 20) toward cooling off. In response, the FOMC changed the directive, which had been aimed at "restraining inflationary developments," to also include taking "into account any deflationary tendencies" (RPA, 1/24/56, p. 19). In March, when "economic activity ... had moved on a plateau during the first quarter of 1956" but "key prices were firm to rising" (RPA, 3/27/56, pp. 25-26), the directive was modified to take out the concern about deflationary tendencies. This tweaking of the directive and policy in response to current and prospective economic conditions was repeated in May, August, and November. There can be no doubt that the Federal Reserve felt a responsibility toward managing the economy in the 1950s and consciously moved aggregate demand to stabilize output and prices.

This evidence of a feeling of responsibility toward real stabilization and inflation control among policymakers in the 1950s is relevant to the hypothesis of this paper. We argue that changes in economic beliefs were a key source of changes in aggregate demand policy. Showing that policymakers were already committed to managing the economy in the 1950 s eliminates the possibility that a changing attitude toward the role of government was a key source of policy changes.

It is also important to point out that as early as the $1950 \mathrm{~s}$, policymakers not only felt a responsibility toward managing aggregate demand, but were able to do so. On the fiscal side, the fact that the high-employment surplus declined substantially in the recessions of 1953-1954 and 1957-1958 is evidence that policymakers were able to negotiate tax and spending changes in response to macroeconomic conditions. On the monetary side, the implementation of policy was also perfectly adequate from the early 1950s on. The Federal Reserve of the 1950s and 1960s has sometimes been criticized for using the imperfect target of free reserves. However, in a previous paper (Romer and Romer, 2002), we show that monetary policymakers in the 1950 s not only complemented their free reserves targets with concern about interest rates, but frequently changed their free reserves target to achieve their interest rate objectives. We also find, contrary to the common assertion, that monetary policymakers in the 1950 s understood the distinction between real and nominal interest rates. Our finding that fiscal and monetary policymakers in the United States were able to manipulate aggregate demand 
effectively starting in the 1950s suggests that improvements in operating procedures could not have been the source of the gross changes in aggregate demand policy that we observe.

Motivation for Policy Actions. The particular aggregate demand policies that monetary and fiscal policymakers took in the 1950s reflected their beliefs about the economy, though with some margin of error. The policy indicators shown in Figures 3 and 4 were quite volatile in the 1950s, suggesting that policymakers may have overreacted to economic developments. And, there were certainly times in the 1950s when policy was expansionary to the point of inflation. This happened, not surprisingly, during the Korean War. Both monetary and fiscal policy were quite loose through late 1952.8 It also happened following the 1953-1954 recession. Both monetary and fiscal policy reacted forcefully to the downturn in the fourth quarter of 1953 and policy remained loose for a number of quarters. As a result, the unemployment rate fell as low as 4\% in 1955 and inflation began to rise.

But, the key feature of the model of the economy held by 1950s policymakers was a belief that that there were no long-run benefits to overexpansion and very high costs to the inflation that would inevitably result. As a result, periods of overexpansion like those in the early and mid-1950s were quickly corrected. And, because inflation was never allowed to get seriously out of hand, the recessions needed to bring inflation down in the 1950s were relatively mild.

There are several examples of aggregate demand policy being used to keep inflation low in the 1950s. The 1956 Economic Report described how fiscal policy was used to fight inflation in 1953:

In the spring of 1953, when inflation was still a real danger, a Message to the Congress recommended that the excess profits tax, which was then in effect, be extended six months beyond its expiration date of June 30, 1953. The decision to extend this burdensome and unpopular tax was taken because it would have been imprudent to increase the deficit and the public debt under the conditions prevailing at the time. (EROP, 1956, p. 73)

Likewise, in the mid-1950s, when inflation reached 4\%, the Federal Reserve took contractionary actions. In 1955, one member of the FOMC said, "I feel that there are inflationary pressures present which should be checked now by a firmer monetary policy - one firm enough to curtail spending and thus dampen price pressures" (Minutes, $11 / 16 / 55$, p. 20, emphasis in the original). Though our estimate of the ex ante real 
federal funds rate rises only for a short period in this episode, monetary contraction in the mid-1950s is widely thought to have been a key cause of the 1957-1958 recession.

Perhaps the policy response most reflective of the economic framework of the 1950s was the tightening in the third quarter of 1958. Chairman Martin and several other members of the FOMC felt that the Federal Reserve had not been quick enough to tighten after the recovery from the 1953-1954 recession and that, as a result, inflation had reemerged in the mid-1950s. As one member stated: "He hoped that the System might stay ahead of the situation better than it did following the 1953-54 recession, with a view to forestalling the results that came to pass later" (Minutes, 9/1/59, p. 20). Determined not to repeat that mistake, the FOMC tightened aggressively soon after the trough of the 1957-1958 recession was reached. The strength of this action can be seen clearly in the rise in the real federal funds rate in late 1958 and 1959 shown in Figure 4. This action, taken in the face of virtually constant actual inflation and anemic real growth, was the result of the Committee's belief that inflation had high costs and no benefits. As one member said, "the Committee was sitting on the edge of what might be almost a volcano. ... Therefore, he felt that it would be a mistake to wait ... before moving to a more restrictive position" (Minutes, 9/1/59, p. 20).

This monetary policy response was clearly supported and augmented by the Eisenhower Administration. The 1959 Economic Report talked approvingly of the "[s]hifts in monetary and credit policy during 1958, and the changes in the underlying economic conditions that called for them" (EROP, 1959, p 106). The 1959 Report also called for fiscal tightening to help restrain inflation. It stated that:

Acceptance by the Congress of the expenditure level of the 1960 budget would be the most important single step in discharging Government's responsibility to help preserve the stability of prices and costs through prudent management of its own financial affairs. (EROP, 1959, p. 51)

As Figure 3 shows, fiscal policy did turn noticeably contractionary in early 1960. Like the monetary contraction, the fiscal contraction was motivated by policymakers' model of the economy. The Eisenhower Administration certainly believed that inflation "would do great harm to our economy" (EROP, 1959, p. 48), and supported lowering aggregate demand as a means of ensuring price stability. 


\section{The 1960s}

The macroeconomic beliefs of the 1960s affected both what policymakers chose to do and what they chose not to do. The effects on what they chose to do were strongest on the fiscal side. Policymakers' belief that the economy could operate at a high level without generating inflation led to the adoption of a wide range of expansionary fiscal measures in 1961 and 1962, the enactment of a major multi-year tax cut in early 1964, and further modest stimulus in 1965. All of these actions were explicitly motivated by the desire to expand economic activity (EROP, 1962, pp. 82-83; 1963, pp. 18-19; 1965, pp. 65-66; 1966, pp. 52-53). In making the case for the 1964 tax cut, which was by far the largest of these measures, the 1964 Economic Report argued that fiscal expansion was necessary because the current unemployment rate was above its normal, sustainable level. It stated:

when demand and incentives are not strong enough to make full use of our manpower and machines, the tax brake is set far too tight.

We need to release that brake quickly to put billions of dollars of new consuming and investing funds into the hands of the private economy. (EROP, 1964, p. 7)

The Report went on to say:

early enactment of the tax bill and enactment of the President's budget for fiscal 1965 will bring a sharp and needed reduction in the full-employment surplus. The tax and expenditure program will ... provide a strong, fresh impetus to the expansion. (EROP, 1964, p. 46)

The combined effect of these actions, together with the initial spending increases resulting from the Vietnam War, reduced the ratio of the high-employment surplus to GDP from $1.6 \%$ at the end of 1960 to $-1.8 \%$ at the end of 1965.

On the monetary side, concern about the balance of payments prevented the FOMC from undertaking any substantial easing in the early 1960s. Thus changes in economic beliefs do not appear to have had a large impact on monetary policy in this period. But in response to this difficulty, policymakers undertook a variety of programs to directly reduce the balance of payments deficit, including the adoption of an "interest equalization tax" in 1963 (EROP, 1962, pp. 13-15; 1964, pp. 127 130; 1966, pp. 165-167). In part because of these programs and expansionary fiscal policy, the constraints on monetary policy stemming from the balance of payments eased considerably by the middle 
of the 1960s. Once this occurred, the FOMC loosened moderately in 1966 and 1967. The real federal funds rate fell by 1.5 percentage points from 1965:3 to 1967:4. This is certainly consistent with the Federal Reserve's belief that unemployment could be reduced substantially without triggering inflation.

The more important impact of the new beliefs on monetary policy in the second half of the 1960s, however, is in what they caused the FOMC not to do: despite high output, low unemployment, and rising inflation, the Federal Reserve kept real interest rates low throughout this period. In retrospect, the meetings in the mid- and late 1960s are remarkable in the degree to which members of the FOMC debated nuances of wording in the directive and small changes in policy, yet failed to address the substantial rise in inflation. The beliefs prevalent at the time of a very optimistic level of normal unemployment and a permanent tradeoff appear to have been the source of this inaction. For example, in early 1968, when inflation was over $4 \%$ and rising, there was still little support for aggressive monetary restraint. One member of the FOMC expressed the common view that

he did not think the Committee should change its position. There was considerable evidence that the main thrust of existing inflationary pressures might be of a short-run nature, and that those pressures might end by the middle of 1968. (Minutes, 1/9/68, pp. 68-69)

The model at the time convinced many members of the FOMC that inflation would disappear on its own if output growth merely returned to normal.

\section{The 1970s}

As described in Section II, the 1970s were a period of rapidly fluctuating beliefs about the macroeconomy. The result was rapidly fluctuating macroeconomic policies.

The triumph of the natural-rate model at the end of the 1960s led to tightening of both monetary and fiscal policy. Policymakers chose to contract aggregate demand because they believed that slack was necessary to reduce inflationary expectations. The real federal funds rate rose from $1.5 \%$ in $1968: 4$ to $3.3 \%$ a year later. Throughout 1969 , the FOMC was willing to accept a level of output below potential to bring inflation down. In October, for example, despite projections of little growth through the middle of 
1970, the Committee "decided that a relaxation of monetary restraint would not be appropriate at this time in light of the persistence of inflationary pressures and expectations" (RPA, 10/7/69, pp. 185-186). Similarly, the ratio of the high-employment surplus to GDP rose from $-1.7 \%$ in 1968 to $-0.3 \%$ in 1969 as a result of a variety of deliberately contractionary fiscal measures aimed at controlling inflation (EROP, 1970, pp. 31-33).

The rapid spread of pessimism about the power of aggregate demand policy to reduce inflation soon led to more radical policy changes, however. Policymakers concluded that the economy was operating well below potential, but that inflation was not falling because it was structural or self-fulfilling. This led them to pursue a two-pronged strategy. One prong was "highly expansionary fiscal policy" (EROP, 1972, p. 108) that resulted in a sharp swing in the high-employment surplus toward deficit in 1971. Since policymakers had come to believe that slack would do little to reduce inflation, they saw no reason to tolerate unemployment above the natural rate. The other prong was wage and price controls

to give the country a period of enforced stability in which expectations, contracts, and behavior will become adapted to the fact that rapid inflation is no longer the prospective condition of American life. (EROP, 1972, p. 108)

The loss of faith in aggregate demand policies led policymakers to adopt unconventional policies aimed at forcibly reducing inflation.

The move to expansionary policy in this period was certainly supported by the Federal Reserve. Our estimate of the real interest rate fell substantially in early 1971 and remained very low through early 1973. The motivation for the Federal Reserve's actions during this period is a matter of substantial debate, and many have suggested that political considerations were paramount. Part of the debate surely stems from the fact that the narrative record is less informative than usual in this period. Nevertheless, we find some evidence that beliefs about how the economy operated were important. For example, in December 1971,

a number of members expressed the view that more aggressive actions to stimulate monetary growth were needed at this time in the interest of fostering the desired expansion of economic activity and employment. In their judgment the risk of rekindling inflationary pressures and expectations by such actions was considerably less now than it had been earlier in the year. (RPA, 12/14/71, p. 199) 
This statement suggests that members of the FOMC favored expansion because they believed that they could lower unemployment without generating inflation. This is certainly consistent with the very optimistic estimates of the natural rate that prevailed among monetary policymakers in the early 1970s.

Policymakers in the middle of the 1970s increased their estimates of the natural rate and began to believe once more that aggregate demand contraction could lower inflation. This change in beliefs was clearly reflected in the switch to contractionary policy that occurred in the middle years of the decade. The real interest rate increased, remaining high well into the recession of 1973-1975. Similarly, the highemployment surplus rose until the third quarter of 1974. Policymakers seemed to almost welcome substantial unemployment because they believed unemployment above the natural rate would eventually reduce inflation. This view was expressed by Chairman Burns, who stated in September 1974 that he "would not wish to see a prompt recovery in economic activity. If recovery began promptly, economic activity would turn up at a time when inflation was continuing at a two-digit rate" (Minutes, 9/10/74, p. $65) .20$

The Carter-era belief that supply shocks were an important source of inflation had little bearing on policy choices in the late 1970s. Once inflation existed, what policymakers chose to do depended on their beliefs about the natural rate and the effectiveness of slack in reducing inflation. And, their belief in this era that the natural rate was relatively low and that inflation was unresponsive to slack was clearly reflected in the policy choices of this period. As Figures 3 and 4 show, both fiscal and monetary policy were noticeably expansionary in 1977 and 1978. The high-employment surplus to GDP ratio fell about $1 / 2$ of a percentage point over this period. The real federal funds rate also fell about $1 / 2$ of a percentage point between late 1976 and mid-1977, and remained very low during much of the Miller era.

The fiscal expansion was a deliberate attempt to lower unemployment. The 1978 Economic

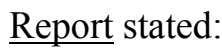

Soon after the new Administration came into office, it proposed a series of measures intended to raise the rate of growth in real output in 1977 and 1978 to a pace that would lead to significant reductions in the unemployment rate. (EROP, 1978, p. 50) 
The 1978 Report also discussed the motivation for the personal income tax reduction that was proposed in 1978 and took effect in January 1979. It said, "without additional fiscal measures, economic growth would slow below the rate necessary to maintain satisfactory progress toward our goal of returning to high employment" (EROP, 1978, p. 73). These policies were clearly motivated by the belief that the current unemployment rate was substantially above the natural rate. There was virtually no discussion in the 1978 Economic Report that such expansion could have adverse inflation consequences. Indeed, the

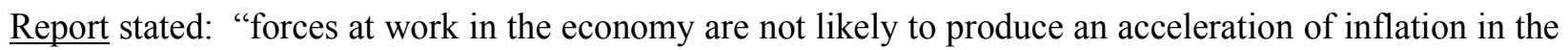
next year or two" (EROP, 1978, p. 152).

The low real interest rates in the late 1970s were largely the result of Federal Reserve inaction, similar to that of the late 1960s. Monetary policymakers in 1978 and 1979 were certainly worried about inflation. For example, in May 1978, "Committee members were deeply concerned about the recent acceleration of inflation and about prospects for prices" (RPA, 5/16/78, p. 175). But throughout this period they were also concerned about real growth and exceedingly cautious in raising interest rates. In early 1978, for example, there was discussion of the desirability of "helping to resist inflationary pressures while simultaneously encouraging continued economic expansion" (PA , 3/21/78, p. 150). A typical discussion from this period ended with a decision like the following: "the Committee concluded that it would be appropriate to await some further evidence on the economic outlook" before deciding "whether further firming at this point would be desirable" (PA, 4/18/78, p. 169). This extremely cautious behavior in the context of inflation rates near double digits and rising is certainly consistent with the low and conflicting estimates of the natural rate among members of the FOMC in this period.

The extreme pessimism about the usefulness of slack in dealing with inflation that dominated the Carter-era model showed up in a rejection of aggregate demand contraction to deal with high and accelerating inflation. The Economic Report for 1979 declared:

We will not try to wring inflation out of our economic system by pursuing policies designed to bring about a recession. That course of action ... would be ineffective. Twice in the past decade inflation has accelerated and a recession has followed, but each recession brought only limited relief from inflation. (EROP, 1979, p. 7, emphasis in the original) 
Instead, as in the early 1970s, the Administration sought to control inflation through a wide range of nonaggregate-demand-based policies. Among the proposals were voluntary wage and price standards, regulatory reform, sales-tax changes, and "real-wage insurance" (EROP, 1978, pp. 18-20, 150-152; 1979, pp. 80-91). A similar view may explain the inaction of monetary policymakers as well. Rather than tighten enough to reduce inflation, some members of the FOMC felt that "prospects for unemployment and prices indicated that active public discussion of some form of an incomes policy would be appropriate" (RPA, 9/20/77, p. 276). Similarly, in early 1978, "[i]t was noted that an effective program to reduce the rate of inflation had to extend beyond monetary policy" (RPA, 3/21/78, p. 150). 21

\section{E. The 1980s and 1990s}

The Volcker disinflation provides one of the most striking examples of the impact of economic beliefs on the conduct of aggregate demand policy. The FOMC undertook a massive and long-lasting shift to tighter monetary policy in October 1979. By our measure, the real federal funds rate rose 6.8 percentage points from 1979:3 to its peak in 1981:3, and it remained high through the mid-1980s.

This policy was unquestionably motivated by the prevailing belief among policymakers that inflation was very costly and that unemployment above the natural rate was the only way to reduce it. At the first meeting of the FOMC after Paul Volcker became Chairman of the Federal Reserve, the Committee discussed "the problems posed by emerging recession and its potential for substantial increases in unemployment," but agreed that "policy measures aimed at reversing the decline in output" were not desirable in light of "the fundamental objective of reducing inflation" (ㄹA, 8/14/79, p. 183). Over the next several years, the Committee repeatedly expressed its willingness to accept high unemployment to bring inflation down (for example, RPA, 7/6-7/81, p. 116; 2/1-2/82, p. 89).

The extreme size of the monetary contraction was clearly influenced by the belief at the time that the natural rate was substantial. In February 1980, when unemployment was already $6.3 \%$, “[m]ost members thought that a moderate contraction in real GNP was likely in 1980, bringing a substantial 
increase in unemployment" (RPA, 2/4-5/80, p. 100); yet they "agreed that monetary growth should slow further in $1980 \ldots$ in line with the continuing objective of curbing inflation” (RPA, 2/4-5/80, p. 102). Members of the FOMC felt that unemployment had to reach substantial levels to bring about the desired reduction in inflation.

The Federal Reserve had the full support of the Reagan Administration in pursuing this policy of disinflation (EROP, 1982, pp. 8, 63-64; 1983, pp. 3, 23).2 Fiscal policymakers agreed that inflation was very costly and that a reduction in aggregate demand was the appropriate policy for reducing it. This is consistent with our finding that fiscal policymakers and monetary policymakers both adopted the modern framework at the start of the 1980s.

The Federal Reserve's continuing concern about inflation, and its continuing belief that substantial unemployment was needed to reduce inflation, led it to react aggressively in the late 1980s to combat a mild resurgence of inflation. Unemployment was in the vicinity of $5.5 \%$ in 1988 . Yet, as documented by Romer and Romer (1994), the Federal Reserve tightened policy in 1988 and 1989 in an active effort to bring inflation down, and believed that higher unemployment and a chance of a recession were the necessary costs of doing so. The real funds rate rose from $3.5 \%$ in $1988: 1$ to $5.5 \%$ in $1989: 1$.

The Federal Reserve's belief that it was important to be forward-looking in conducting policy certainly influenced its behavior in the 1990s. For example, it tightened moderately in 1994 and 1997 in response to risks of inflation that had not yet materialized (see, for example, RPA, 2/3-4/94, pp. 131, 134, $137 ; 3 / 25 / 97$, pp. 118-121), and loosened in 1998 in response to the potentially contractionary effects of turbulence in foreign financial markets (RPA, 9/29/98, pp. 178-181; 11/17/98, pp. 189-193). These actions were consistent with the Federal Reserve's belief that it was better to counteract developments before they occurred than after.

The evolution of beliefs continued to affect the conduct of monetary policy in the late 1990s. As is well known, the FOMC's conclusion that changes in the economy had raised the growth rate of potential output and at least temporarily lowered the natural rate of unemployment led it to raise the federal funds rate only moderately in face of rapid output growth and low unemployment. Further, the 
Committee's perception of substantial changes in the economy made it more uncertain about the level of potential output, causing it to become less aggressive in moving preemptively. In February 2000, for example, the Committee moved to tighten "in an effort to avert rising inflationary pressures." However, "[f]or a number of reasons, including uncertainties about the outlook for the expansion of aggregate demand in relation to that of potential supply, ... a majority of the members expressed a preference for a

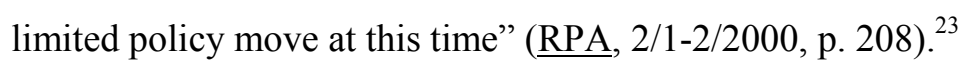

\section{POLICYMAKERS' BELIEFS AND DEPARTURES FROM A MODERN MONETARY POLICY RULE}

It is possible to supplement the narrative analysis of policy choices with a more systematic examination of the conduct of monetary policy. In particular, we can examine how the response of monetary policy to a given set of economic conditions has changed over time, and ask whether the changes appear to be related to changes in economic beliefs.

\section{A. Method}

To implement this idea, we begin by estimating a monetary policy rule over the period since October 1979. As described in Section II, the central features of monetary policymakers' views of the economy have been quite stable over this period. As a result, estimates from this period should provide a reasonable description of how modern monetary policymakers respond to economic conditions. We then compare the implications of this rule with the actual conduct of policy not just over the period since 1979, but over the entire period since the early 1950s. We ask whether there are systematic differences between the actual conduct of policy and the rule's predictions in periods when policymakers' views of the economy differed substantially from modern views. 24

A standard modern prescription for monetary policy, following Taylor (1993), relates the central bank's choice of the real interest rate relative to its equilibrium level to the departure of inflation from the 
central bank's target level and the deviation of output from its normal or trend level. A linear version of this prescription is:

$$
r_{t}=r_{t}^{E Q}+a\left(\pi_{t}-\pi^{*}\right)+b\left(Y_{t}-\bar{Y}_{t}\right)
$$

Here $r$ is the ex ante real interest rate, $\mathrm{r}^{\mathrm{EQ}}$ is the equilibrium real rate, $\pi$ is inflation, $\pi^{*}$ is target inflation, $\mathrm{Y}$ is the $\log$ of output, and $\overline{\mathrm{Y}}$ is the $\log$ of normal or trend output. a and $\mathrm{b}$ are positive parameters.

There are several issues that must be addressed before (3) can be estimated. The first issue is the measurement of the equilibrium real interest rate. Figure 4 shows that the ex ante real rate has been trending up over the postwar period; this trend presumably mainly reflects movements of the equilibrium real rate. To deal with this, we estimate the equilibrium real rate by interpolating linearly between two periods when output was close to trend and the real interest rate was fairly stable: 1962 (when the deviation of output from trend averaged $-0.1 \%$ and the real interest rate averaged $1.1 \%$ ), and 1997-1998 (when the deviation of output from trend averaged $0.1 \%$ and the real interest rate averaged $3.6 \%$ ). We then work with the deviation of the ex ante real interest rate from this trend.

The second issue is the measurement of inflation, actual output, and trend output. Following Taylor, in our baseline specification we measure inflation as the change in the log GDP deflator over the previous 4 quarters and actual output as log real GDP in the current quarter. We compute trend output using a Hodrick-Prescott filter applied to log real GDP over the period 1952:1-2000:4.

The third issue is that the Federal Reserve typically adjusts the real interest rate gradually. We therefore include the lagged dependent variable in the equation. Without this modification there would be severe serial correlation in the errors.

With these changes, equation (3) becomes

$$
\mathrm{r}^{\mathrm{DT}}=\alpha+\beta \pi_{\mathrm{t}}+\gamma\left(\mathrm{Y}_{\mathrm{t}}-\overline{\mathrm{Y}}_{\mathrm{t}}\right)+\rho \mathrm{r}_{\mathrm{t}-1}^{\mathrm{DT}}
$$

where $\mathrm{r}^{\mathrm{DT}}{ }_{\mathrm{t}}$ is the detrended ex ante real interest rate and $\alpha$ reflects the target rate of inflation. 


\section{B. Results}

We estimate this equation over the post-Volcker sample period of 1979:4-2000:3 using ordinary least squares. 25 The estimated equation is:

$$
\begin{aligned}
\mathrm{r}^{\mathrm{DT}}{ }_{\mathrm{t}}= & -0.39+0.17 \pi_{\mathrm{t}}+0.14\left(\mathrm{Y}_{\mathrm{t}}-\overline{\mathrm{Y}}_{\mathrm{t}}\right)+0.83 \mathrm{r}^{\mathrm{DT}}{ }_{\mathrm{t}-1}, \\
& (0.17)(0.05) \quad(0.06)
\end{aligned}
$$

where the numbers in parentheses are standard errors. The $\mathrm{R}^{2}$ of the regression is 0.88 and the standard error of the estimate is 0.76 .

Equation (5) implies that over the post-1979 period, the real interest rate has responded positively and significantly to inflation and output. With a lagged dependent variable in the equation, the implied long-run responses of the real interest rate to inflation and output are given by $\beta /(1-\rho)$ and $\gamma /(1-\rho)$, respectively. Thus, because of the high estimate of $\rho$, the long-run responses of the real interest rate implied by (5) are substantial: a rise in inflation of one percentage point leads to a rise in the detrended real rate of 0.97 percentage points, and a rise in the deviation of output from trend of one percentage point leads to a rise in the detrended real rate of 0.81 percentage points.

Figure 5 compares the predictions of the estimated rule with the actual (detrended) real interest rate over the entire postwar period. The predictions of the rule shown in the figure are the implied longrun responses. That is, the value shown for quarter $\mathrm{t}$ is $\left[\alpha+\beta \pi_{t}+\gamma\left(\mathrm{Y}_{\mathrm{t}}-\overline{\mathrm{Y}}_{\mathrm{t}}\right)\right] /(1-\rho)$.

As many authors have noted, the actual funds rate tracks the rule fairly closely over the post-1979 period. The largest in-sample departures are early in the Volcker era. Even after the regime shift in October 1979, the real interest rate remained well below the value implied by the rule for a considerable period. The gap narrowed substantially from the extremely high levels of the years immediately preceding the regime shift. But the estimates in (5) imply that had policymakers responded to the very high inflation rates of late 1979 and 1980 in a manner typical of their behavior over the entire post-1979 period, they would have pursued even more contractionary policies. It was not until 1981:2 that the 
actual rate was within 2 percentage points of the value prescribed by the rule. There were large departures from the rule in the opposite direction in 1982-1983. During this period, the actual funds rate was more than 4 percentage points above the value implied by the rule for six quarters in a row.

These early departures from the estimated rule may have been the result of policymakers' emphasis on monetary aggregates in this period. Another possibility is that they stemmed from policymakers' uncertainty about the strength of the measures needed to accomplish their anti-inflationary objectives. The departures in 1979-1980 could also have arisen in part from a belief among monetary policymakers that there were political constraints on how quickly and strongly they could act, particularly just before a Presidential election.

A final modern period when actual behavior departed significantly from the predictions of the rule was 1992-1993, when the actual rate was quite low relative to the predicted values. This presumably reflects the Federal Reserve's concern about the "credit crunch" of the early 1990s.

The more important message of Figure 5, however, concerns the period before the emergence of the modern beliefs about stabilization policy. Between the fourth quarter of 1965 and the third quarter of 1979 , the actual real rate was below the rate implied by the rule in every quarter except one. The average gap over the period 1965:4-1979:3 was 4.0 percentage points. Thus, monetary policy was substantially more expansionary than a modern rule would predict for nearly fifteen years.

While the gap is substantial in virtually all of the years, it is largest in the 1970s. To a large extent, this reflects the fact that inflation was higher in the 1970s. Policymakers in the 1960s were faced with high output and low or moderate inflation. They chose to keep the real interest rate near its equilibrium level, and so departed moderately from the prescriptions of the rule. Policymakers in the 1970s were faced with high inflation and output fluctuating around its sustainable level. They chose to keep the real interest rate low, and so departed dramatically from the rule's prescription that the appropriate response to high inflation is a very high real rate.

That the deviations from what a post-1979 rule predicts are so large and so persistent in the 1960s and 1970 s casts doubt on the plausibility of some alternative explanations for policymakers' behavior. 
For example, individual personalities, idiosyncratic political forces, and imperfect monetary targets are all factors that could influence policy for perhaps a few quarters or even a few years at a time, but not decades. Similarly, an unnoticed productivity slowdown or supply shocks might be able to explain inflationary aggregate demand policy for a few years in the 1970s, but cannot explain the large and persistent shifts that occurred. Fundamentally, running very expansionary policy for nearly 15 years almost surely had to be a conscious decision, not an accident or miscalculation.

The decision to run expansionary policy in the 1960s and 1970s was completely consistent with the beliefs held by policymakers at the time. As shown in Section II, for most of this time policymakers had very optimistic views about sustainable output growth and the ease of reducing inflation (and, at times, about the prospects for achieving permanently low unemployment). As a result, when faced with a given level of output and inflation, they followed dramatically more expansionary monetary policy than their modern counterparts would have. Also, in the early and late 1970s, policymakers came to believe that tightening would do little to reduce inflation. As a result, when faced with inflation they chose not to raise rates, as a modern rule would call for.

Finally, Figure 5 shows that the real rate did not depart systematically from the predictions of the rule in the 1950s and early 1960s. Policy was noticeably tighter than the rule's prescriptions in 1954, noticeably looser in 1956-1957, and noticeably tighter again in 1963-1964. On average, the actual real interest rate in the period 1953:1-1965:4 was higher than that predicted by the modern rule, but only by 0.4 percentage points. Similarly, over the shorter period 1953:1-1960:4, the actual real rate was on average lower than the rule's prediction, but again only by 0.4 percentage points.

This fundamental similarity between monetary policy actions in the 1950s and those in the 1980s and 1990s is exactly what one would expect given the fundamental similarity in policymakers' beliefs in the two periods. Like their modern counterparts, monetary policymakers in the 1950 s had a realistic estimate of sustainable unemployment and a firm belief that overexpanding to the point of inflation would have adverse consequences. As a result, they pursued policies designed to keep inflation in check, while counteracting short-run deviations of output from trend, just as modern policymakers have. 
That there were more substantial departures from the prescriptions of a modern rule in the 1950s and early 1960s than in the post-1980 period could just reflect changes in economic relationships between the 1950s and the last two decades of the twentieth century. One would expect out-of-sample prediction errors to be larger than in-sample errors. But, the larger departures in the early period are also consistent with the fact that the model used by policymakers in the 1950s was cruder and less carefully calibrated than the model used today. The cruder model, together with the early Federal Reserve's use of imperfect policy indicators, could easily have caused substantial transitory deviations from the prescriptions of a modern rule. But, the fundamental similarity in the early and late frameworks made the departures average roughly zero over the decade. That policymakers in the 1950 s chose aggregate demand policies that look like modern choices but with a large random error is exactly what one would expect given the evolution of beliefs that has occurred.

\section{CONCLUSION}

There have been large changes in the conduct of stabilization policy in the United States over the past half-century. In the 1950s, policymakers cautiously balanced concerns over inflation and real activity; in the 1960s, they focused vigorously on increasing real activity; in the 1970s, they pursued policies ranging from rapid expansion to full-fledged contraction to grudging tolerance of inflation; in the early 1980s, they followed a policy of aggressive disinflation; and since that time, they have again cautiously balanced the pursuit of real growth with concern about the possibility of inflation.

It is tempting to attribute these large variations in policy to variations in politics, ideology, or policymakers' underlying objectives. The evidence in this paper suggests, however, that an alternative hypothesis explains the main changes in macroeconomic policy. Our evidence shows that changes in economic understanding have been central to the evolution of stabilization policy. Throughout the postwar period, policymakers' fundamental goals have been the same: high growth, low inflation, and 
stability. But as policymakers' understanding of the economy evolved, the policies they adopted in pursuit of those fundamental objectives evolved.

In the 1950s, policymakers believed that the economy's capacity was clearly limited, that efforts to push the economy beyond that capacity would quickly produce inflation, and that inflation had substantial and rapid costs. As a result, while seeking to avoid downturns, they were extremely concerned about inflation and acted aggressively to try to prevent it. In the 1960s, policymakers thought that the economy's capacity was large, that expansion would have at most only moderate inflationary effects, and that modest inflation would not prevent the economy from operating at high levels. As a result, they moved aggressively to attempt to stimulate the economy to high levels of activity. In both the early and late 1970s (though less so in the middle of the decade), policymakers believed that inflation was almost impervious to slack in real activity. They therefore refrained from using significant aggregate demand restraint to attempt to control inflation and pursued a variety of nontraditional policies. Finally, in the 1980s policymakers concluded that nontraditional policies would not work, that traditional policies would, and that inflation was very harmful. They therefore moved aggressively to reduce inflation, and then tried to promote real activity while acting quickly to prevent or reverse even moderate resurgences of inflation.

Our analysis has focused on the role of policymakers' beliefs in explaining the evolution of aggregate demand policy in the United States. It is certainly the case, however, that similar gross changes in stabilization policy occurred in most industrialized countries. Throughout much of the industrialized world, policy developed an expansionary bias in the 1960s that continued into the 1970s, but ended by the 1980s. That these changes were so universal is strong evidence that idiosyncratic factors, such as politics and institutions, were not key. At the same time, beliefs about how the economy works tend to be correlated across countries, and so could provide an explanation for the worldwide changes that occurred. The obvious test of this conjecture would be to examine narrative evidence from other countries to determine whether the evolution of economic understanding that we observe in the United States was indeed an international phenomenon. 
Our findings about the key role of economic understanding in the evolution of policy suggest both a note of optimism and a note of caution about the future of stabilization policy. The optimistic note is that because changes in economic understanding have been important to changes in the conduct of policy, policy should on average improve over time. If changes in policy were the result of changes in objectives and ideologies, we would expect to observe continual fluctuations in the conduct of policy as the political process produced leaders and policymakers with different goals and values. But accumulated experience, additional data, and new insights should lead to improvements in economic understanding over time, and thus to improvements in policy. For example, it seems very unlikely that modern policymakers faced with economic circumstances like those of the 1960s and 1970s would advocate the expansionary policies that were pursued then.

The note of caution is that while knowledge on average improves over time, its progress is not uniform. The history of policymakers' beliefs in the postwar era shows that there have been some twists and turns in economic understanding that have led to undesirable policies and outcomes. Policymakers in the 1950s appear to have had a more accurate assessment of the economy's capacity than their successors in the 1960s and 1970s, and a view of the effects of inflation that led them to more appropriate policies. Thus we cannot be confident that economic beliefs and the policies derived from them will continue to improve, or even that they will not worsen at times. Future policymakers therefore face the difficult task of distinguishing between genuine advances in economic understanding and appealing, but ultimately flawed, new ideas. 
Table 1

Summary Statistics for Greenbook Inflation Forecast Errors

\begin{tabular}{|c|c|c|c|c|c|c|c|c|}
\hline & $\frac{\text { Martin }}{(67: 10-70: 1)}$ & $\begin{array}{r}E \\
(70: 2-75:\end{array}$ & $\frac{\text { Irns }}{(75: 7-78: 2)}$ & $\frac{\text { Miller }}{(78: 3-79: 7)}$ & $\frac{\text { Volcker }}{(79: 8-87: 7)}$ & $\frac{\text { Greenspan }}{(87: 8-96: 12)}$ & $\frac{\text { Pre-Volcker }}{(67: 10-79: 7)}$ & $\frac{\text { Post-Volcker }}{(79: 8-96: 12)}$ \\
\hline $\begin{array}{l}\text { Root Mean } \\
\text { Square Error }\end{array}$ & 1.1 & 2.2 & 1.1 & 1.1 & 0.8 & 0.5 & 1.7 & 0.7 \\
\hline $\begin{array}{l}\text { Average } \\
\text { Forecast Error }\end{array}$ & 1.0 & 1.3 & -0.2 & 0.9 & -0.4 & -0.3 & 0.8 & -0.3 \\
\hline $\mathrm{N}$ & 20 & 61 & 32 & 15 & 66 & 76 & 128 & 142 \\
\hline
\end{tabular}

The inflation forecast errors are for forecasts of average inflation at an annual rate in the quarter of the forecast and the subsequent two quarters. The data are in percentage points. 
Table 2

Summary Statistics for the Natural Rate of Unemployment Implicit in Greenbook Forecasts

\begin{tabular}{|c|c|c|c|c|c|c|c|c|}
\hline & $\frac{\text { Martin }}{(67: 10-70: 1)}$ & $\begin{array}{r}\text { B } \\
(70: 2-75: 6\end{array}$ & $\begin{array}{l}\frac{\mathrm{ns}}{(75: 7-78: 2)} \\
\end{array}$ & $\frac{\text { Miller }}{(78: 3-79: 7)}$ & $\frac{\text { Volcker }}{(79: 8-87: 7)}$ & $\frac{\text { Greenspan }}{(87: 8-96: 12)}$ & $\frac{\text { Pre-Volcker }}{(67: 10-79: 7)}$ & $\frac{\text { Post-Volcker }}{(79: 8-96: 12)}$ \\
\hline Mean & $2.5 \%$ & $3.1 \%$ & $8.2 \%$ & $4.6 \%$ & $8.0 \%$ & $6.7 \%$ & $4.5 \%$ & $7.3 \%$ \\
\hline $\begin{array}{l}\text { Standard } \\
\text { Deviation }\end{array}$ & 1.6 & 3.5 & 2.5 & 2.2 & 2.4 & 1.8 & 3.6 & 2.2 \\
\hline $\mathrm{N}$ & 20 & 61 & 32 & 15 & 66 & 76 & 128 & 142 \\
\hline
\end{tabular}

The implicit estimates of the natural rate are computed from the forecasts of unemployment and the change in inflation in the quarter of the forecast and the two subsequent quarters. See text for details. 
Figure 1

Average Greenbook Forecast Errors for Inflation

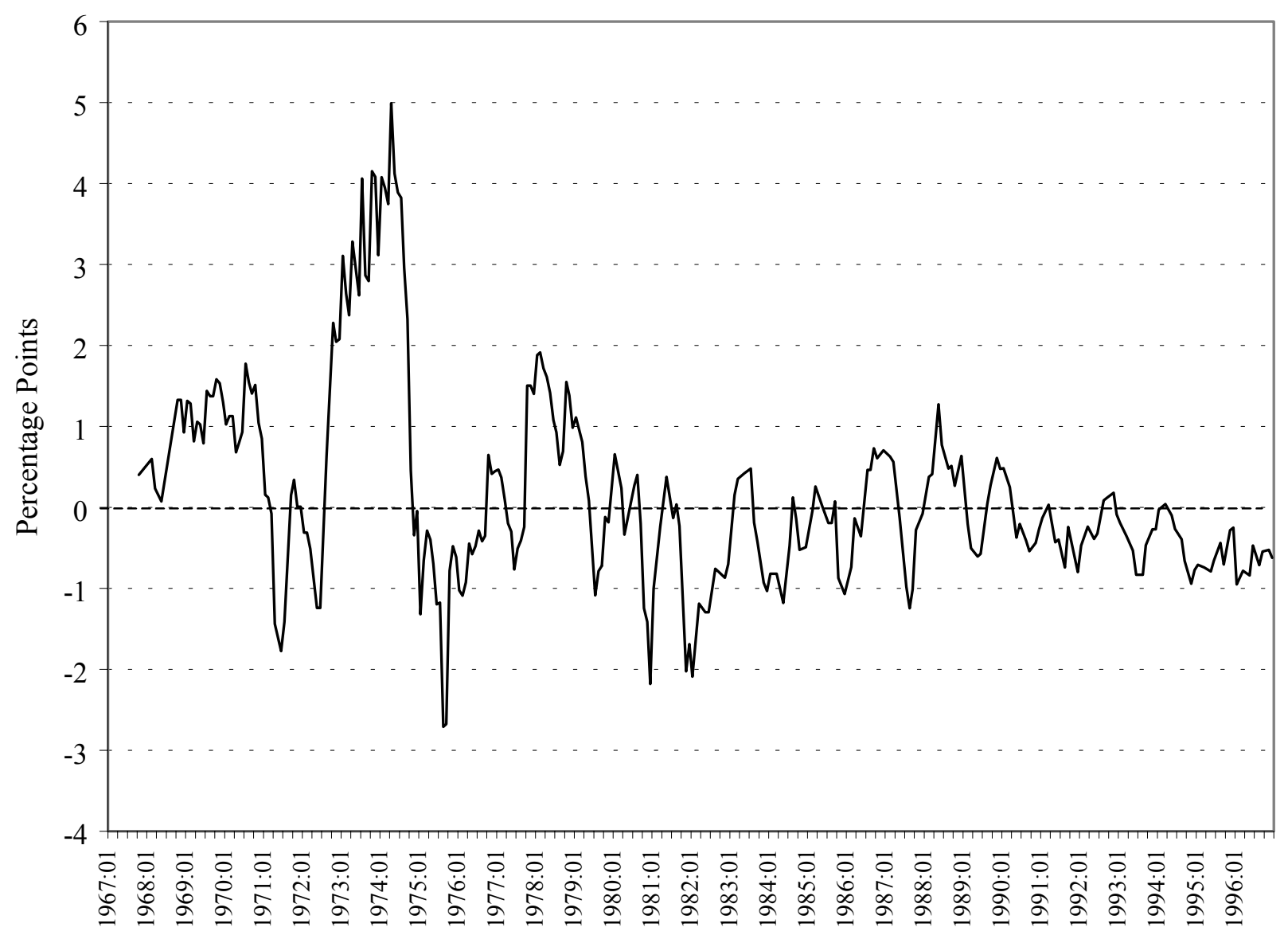


Figure 2

Natural Rate of Unemployment Implicit in Greenbook Forecasts

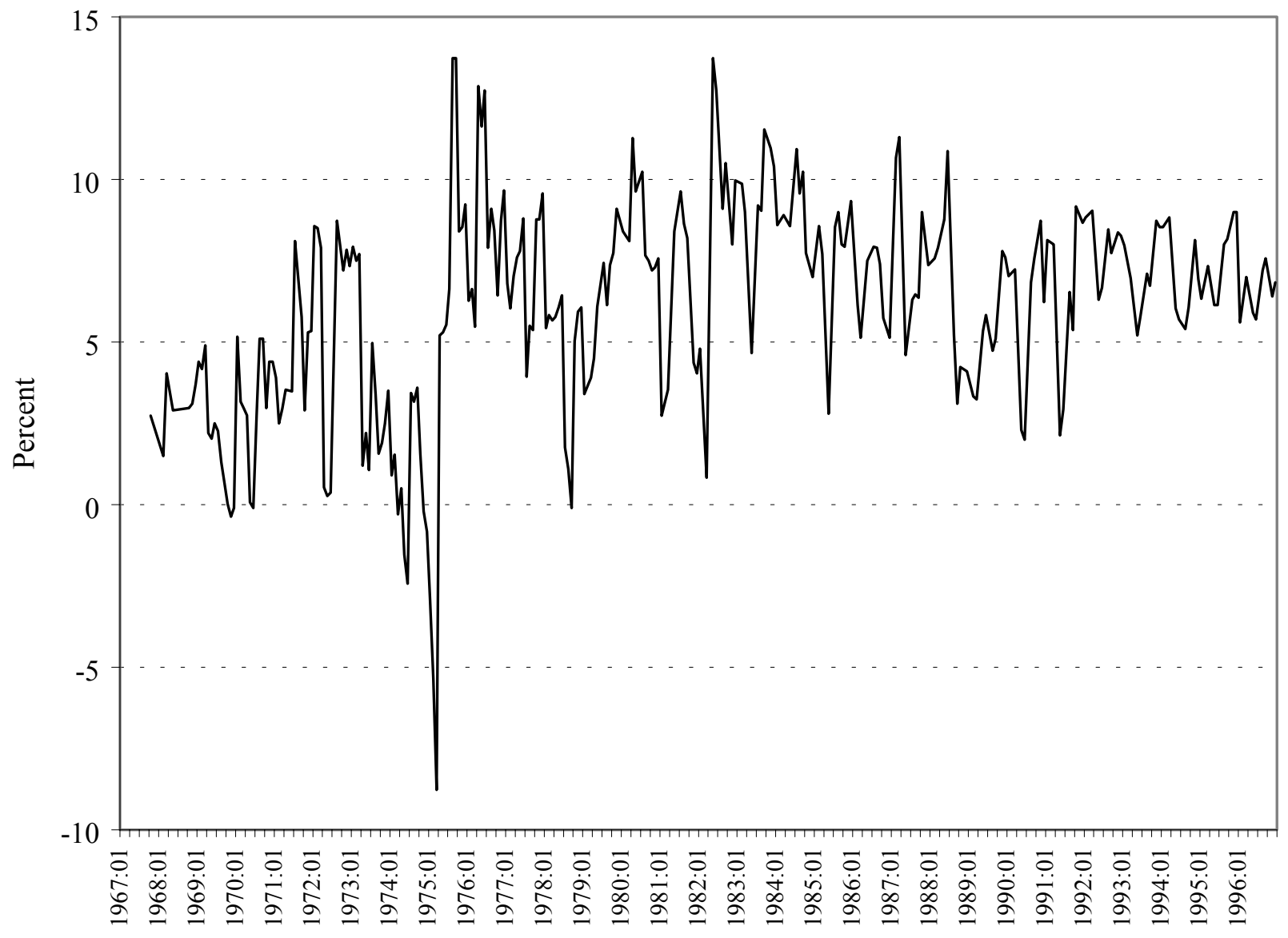


Figure 3

Ratio of High-Employment Surplus to Potential GDP

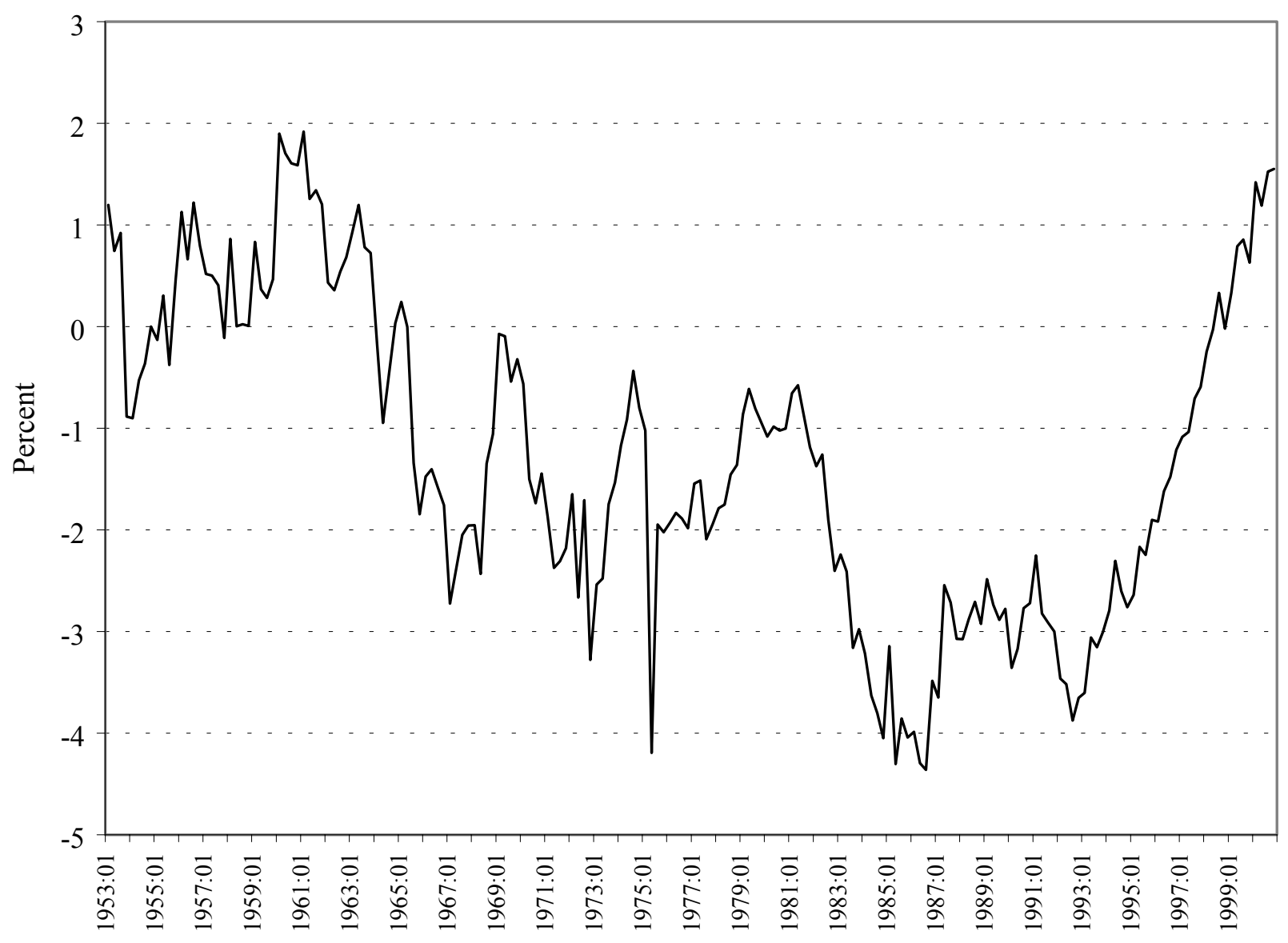


Figure 4

Ex Ante Real Federal Funds Rate

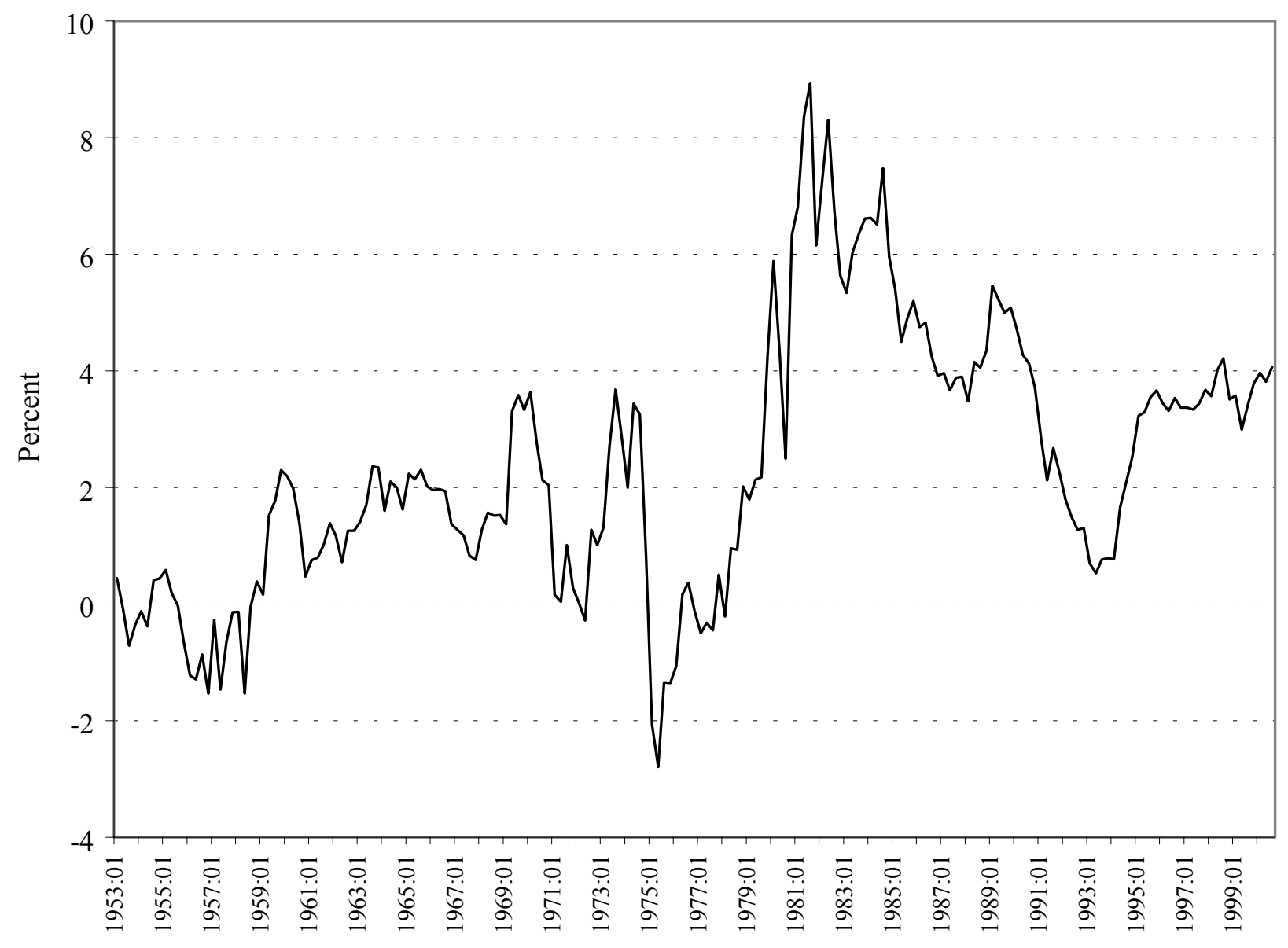


Figure 5

Actual Real Federal Funds Rate

and Predicted Rate from a Post-1979 Monetary Rule

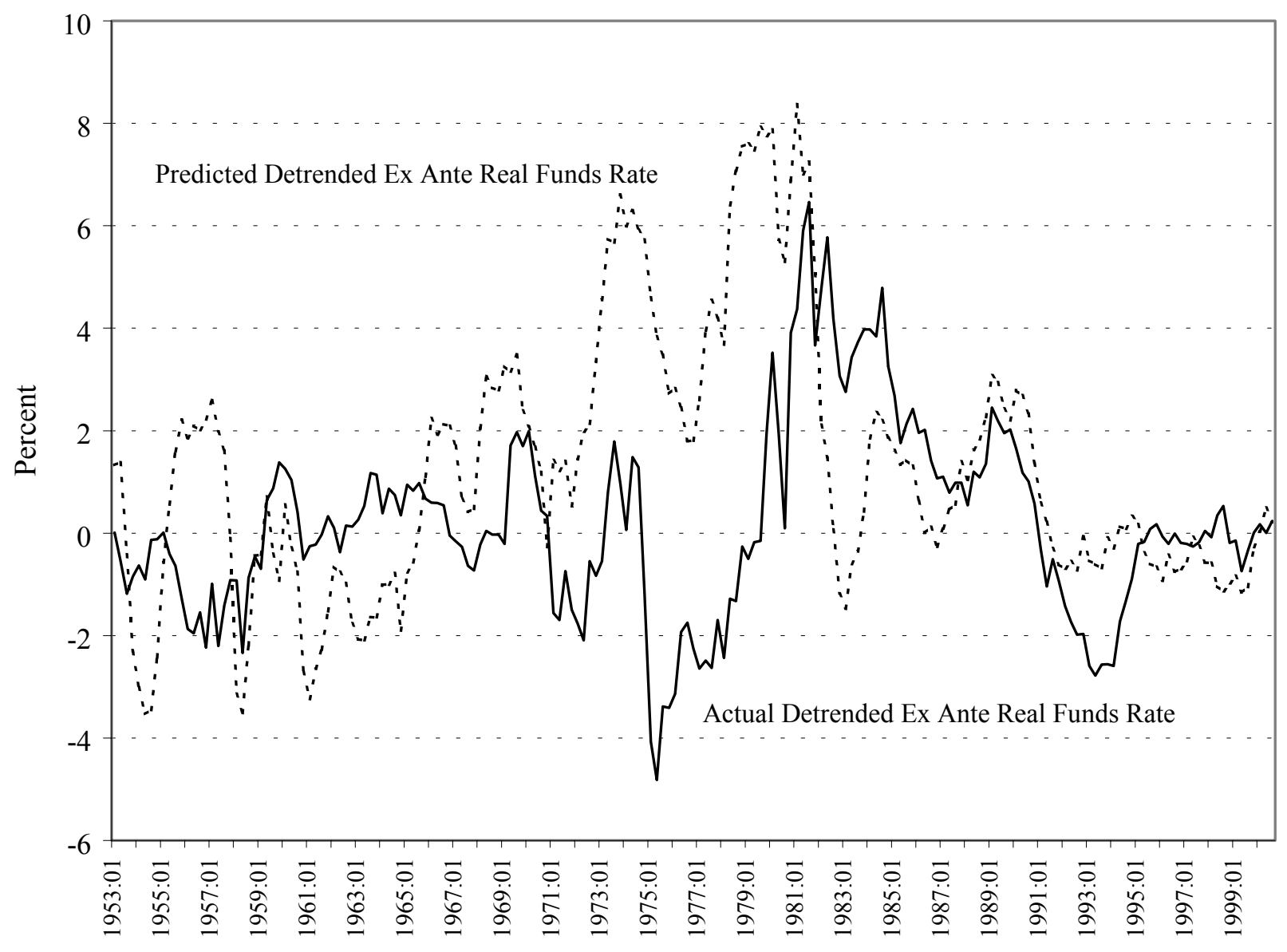




\section{REFERENCES}

Clarida, Richard, Jordi Galí, and Mark Gertler. "Monetary Policy Rules and Macroeconomic Stability: Evidence and Some Theory." Quarterly Journal of Economics 115 (February 2000): 147-180.

DeLong, J. Bradford. “America's Peacetime Inflation: The 1970s.” In Reducing Inflation: Motivation and Strategy edited by Christina D. Romer and David H. Romer (Chicago: University of Chicago Press for NBER, 1997), pp. 247-276.

Dornbusch, Rudiger, Stanley Fischer, and Richard Startz. Macroeconomics. Eighth Edition. (New York: McGraw-Hill, 2001).

Greenspan, Alan. "Current Monetary Policy.” Speech at the Stern School of Business, May 8, 1997.

Martens, Edward J. Federal Funds: A Money Market Device. Unpublished manuscript, Pacific Coast Banking School, April 1958.

Mayer, Thomas. Monetary Policy and the Great Inflation in the United States: The Federal Reserve and the Failure of Macroeconomic Policy, 1965-79 (Cheltenham, UK: Edward Elgar, 1998).

Meyer, Laurence H. "The Economic Outlook and the Challenges Facing Monetary Policy." Speech at Washington University, October 19, 2000.

Mishkin, Frederic. "The Real Interest Rate: An Empirical Investigation." Carnegie-Rochester Conference Series on Public Policy 15 (Fall 1981): 151-200.

Orphanides, Athanasios. “The Quest for Prosperity without Inflation.” European Central Bank Working Paper No. 15, March 2000.

Romer, Christina D., and David H. Romer. "Monetary Policy Matters.” Journal of Monetary Economics 34 (August 1994): 75-88.

Romer, Christina D., and David H. Romer. "A Rehabilitation of Monetary Policy in the 1950s.” American Economic Review 92 (May 2002): 121-127.

Rudebusch, Glenn D. “Term Structure Evidence on Interest Rate Smoothing and Monetary Policy Inertia.” Unpublished manuscript, Federal Reserve Bank of San Francisco, August 2001. Journal of Monetary Economics, forthcoming.

Taylor, John B. "Discretion versus Policy Rules in Practice." Carnegie-Rochester Conference Series on Public Policy 39 (December 1993): 195-214.

Taylor, John B. "Comment." In Reducing Inflation: Motivation and Strategy edited by Christina D. Romer and David H. Romer (Chicago: University of Chicago Press for NBER, 1997), pp. 276280.

Taylor, John B. "A Historical Analysis of Monetary Policy Rules." In Monetary Policy Rules edited by John B. Taylor (Chicago: University of Chicago Press for NBER, 1999), pp. 319-341.

U.S. Board of Governors of the Federal Reserve System. Annual Report. Various years. 
U.S. Board of Governors of the Federal Reserve System. Minutes of the Federal Open Market Committee. Various years.

U.S. Board of Governors of the Federal Reserve System. Transcripts of Federal Open Market Committee. Various years.

U.S. Office of the President. Economic Report of the President. Various years. 


\section{ENDNOTES}

${ }^{1}$ In his discussion of DeLong's paper, Taylor (1997) makes an argument similar to Mayer's.

${ }^{2}$ In a most confusing development, these brief summaries were renamed the Minutes of Federal Open Market Committee Meetings in the early 1990s. To avoid confusing these brief summaries with the detailed Minutes for the pre-1976 period, we continue to cite the shorter summaries as the Record of Policy Actions. The Record of Policy Actions for a year is reproduced in that year's Annual Report of the Board of Governors of the Federal Reserve System. In the citations to the Record of Policy Actions that follow, the page numbers refer to the Annual Report. Because neither the detailed Minutes nor the Transcripts are currently available for the period 1976 to 1980 or 1997 to the present, we use only the Record of Policy Actions for these years.

${ }^{3}$ The discussion of monetary policymakers' beliefs in the 1950s in this section and in Section IV draws heavily on Romer and Romer (2002).

${ }^{4}$ In describing the situations that policymakers found themselves in, for simplicity we cite modern data in cases (such as this one) where they are similar to the estimates that policymakers had at the time. Whenever the difference between the contemporaneous and modern figures is non-negligible, however, we use the contemporaneous figure and make clear that it was the estimate available at the time.

${ }^{5}$ The 1966 Economic Report argued that changes in the labor market had lowered the feasible unemployment rate to well below 4\% (EROP, 1966, pp. 42, 75-76). Later reports reverted to the 4\% figure, however.

${ }^{6}$ Policymakers in the 1960s did acknowledge that current inflation depended not just on unemployment, but on the inherited inflation rate as well. For example, policymakers at the beginning of 1967, with unemployment at 3.9\%, stated: "A healthy advance of demand in pace with the growth of potential output would permit gradual restoration of price stability" (EROP, 1967, p. 38). Similarly, for 1968 they expected "the unemployment rate to remain below 4 percent" with "a gradual slowing down of price increases" (EROP, 1968, p. 11).

${ }^{7}$ See especially the discussion of discount rate policy in the 1974 Annual Report of the Board of Governors of the Federal Reserve System, pp. 107-110.

${ }^{8}$ Governor Meyer (2000) provided a particularly clear statement of this view.

${ }^{9}$ We obtain this series from the Survey of Current Business (typically from the March, June, September, and December issues). We calculate the inflation rate using data on both the quarter in question and the previous quarter from the same issue of the Survey. We switch from GNP data to GDP data in November 1991, when the Federal Reserve switched what it forecasts.

${ }^{10}$ Missing values are dealt with in the figure by interpolating between available observations. These values are not used in calculating the summary statistics in Table 1.

${ }^{11}$ The pessimism about the sensitivity of inflation to slack in the early and late 1970s could have caused the Federal Reserve to overpredict inflation if it had been coupled with a realistic estimate of the natural rate and contractionary policy. But, because estimates of the natural rate were very optimistic and serious contractionary policies were not attempted in these periods, one would not expect to in fact observe overprediction.

${ }^{12}$ See, for example, Dornbusch, Fischer, and Startz (2001, p. 109). Reasonable variations in the assumed sensitivity of inflation have little impact on the results.

${ }^{13}$ Missing values are again dealt with in the figure by interpolating between available observations. The interpolated values are not used in computing summary statistics. 
${ }^{14}$ The high implicit estimates of the natural rate in the mid-1970s could be due to forecasts of supply shocks. As described in Section II, policymakers in this period began to believe that supply shocks were important. Since our calculation of the implicit estimate of the natural rate is done under the simplifying assumption that all forecasted movements in inflation are due to deviations of unemployment from the natural rate, forecasts of unfavorable supply shocks could make our deduced estimates of the natural rate larger than the actual beliefs of the forecasters. One piece of evidence that such forecasts of supply shocks could have been present in some forecasts in this period comes from the Record of Policy Actions for September 16, 1975. At this meeting, "Staff projections continued to suggest ... somewhat faster rise in average prices than in the first half, mainly reflecting increases in prices of food and energy products" (PA, 9/16/75, pp. 224-225).

${ }^{15}$ The unpublished quarterly values are derived by interpolating the CBO's annual figures.

${ }^{16}$ The funds rate data that we use are quarterly averages from Citibase (August 2001). These data are available from 1954:1 to the present. We extend this series back to 1950:1 using data from Martens (1958). The data in Martens are given only in a figure. We deduced the estimates from the graph and then calibrated and checked our estimates using a period of overlap between the Martens data and the Citibase series.

${ }^{17}$ The data on real GDP and the GDP implicit price deflator are also from Citibase (August 2001). The funds rate data that we use are quarterly averages. Therefore, one wants inflation over the same quarter. To construct this, we average the GDP deflator from a given quarter $(\mathrm{t})$ and the quarter before. The rate of inflation between $\mathrm{t}$ and $\mathrm{t}+1$ derived from this averaged series approximately reflects inflation from the start to the end of a given quarter. We calculate trend output for 1952:1 to 2000:4 by applying a Hodrick-Prescott filter to log real GDP.

${ }^{18}$ We cannot calculate the ex ante real rate for the very early 1950s because we use lags of the federal funds rate in the estimation and our data on the funds rate do not start until 1950. However, the ex post real rate was extremely low (substantially negative) in 1950 and 1951, when nominal rates were low and inflation was high.

${ }^{19}$ The slight additional fall in this ratio over the next few years was largely the result of the war, however, and not of deliberate fiscal stimulus.

${ }^{20}$ See also the many similar statements by participants in the September 10, 1974 FOMC meeting quoted by Mayer (1998, p. 131).

${ }^{21}$ Orphanides (2000) argues on the basis of statistical evidence that the major shifts in monetary policy in the period 1965-1993 were due largely to changes in policymakers' estimates of the path of actual output relative to the economy's potential. Our narrative evidence confirms Orphanides's conclusion that changing views about the output gap were important to the conduct of policy. But it shows that other aspects of policymakers' beliefs - the belief in a long-run tradeoff in the 1960s and, especially, the pessimism about the responsiveness of inflation to slack at various times in the 1970s - were also important to the conduct of policy. In addition, it seems unlikely that policymakers' estimates of the economy's potential were independent of other aspects of their beliefs. For example, during most of the 1960s and 1970s, estimates of the natural rate of unemployment were $4 \%$ or below. Since actual unemployment only rarely reached those levels, policymakers with a modern natural-rate framework and the information available at the time almost surely would have had higher estimates.

${ }^{22}$ The final Economic Report of the Carter Administration was more circumspect: although it stated the Administration's support for the Federal Reserve's policies, it focused mainly on the dangers of rigid adherence to money targets (EROP, 1981, pp. 13-14, 50-57).

${ }^{23}$ As described in Section II, the evolution of the high-employment surplus over the last twenty years largely reflected policymakers' views about the proper size of government and the supply-side effects of tax cuts, not their beliefs about aggregate demand policy.

${ }^{24}$ Taylor (1999) performs a similar exercise. Rather than using an estimated rule for comparison with actual policy, however, he imposes coefficient values a priori. In addition, he does not account for the upward trend in the 
equilibrium real interest rate, and he does not consider the 1950s. He reaches broadly similar conclusions to ours about monetary policy since 1960 .

${ }^{25}$ The results are robust to two natural variations. The first, following Clarida, Galí, and Gertler (2000), is to estimate a forward-looking variant of (4). Specifically, we replace the measures of inflation and the output gap in equation (4) with inflation from quarter $t$ to quarter $t+1$ and the deviation of output from trend in quarter $t+1$. We then estimate the equation by instrumental variables, instrumenting with variables known at time t; we use the current value and two lags of inflation and of the deviation of output from trend (plus the lagged dependent variable and the constant) as the instruments. The results are quite similar to those in equation (5). The second variation, following Rudebusch (2001), is to replace the lagged dependent variable in the equation with an assumption that the error term follows an AR-1 process. The idea behind this specification is that the serial correlation of the departures of the funds rate from the predictions of a rule based on output and inflation may reflect not gradual adjustment by the Federal Reserve, but the presence of additional factors influencing the Federal Reserve's choice of the real rate that are serially correlated. This approach implies somewhat smaller responses of the real rate to inflation and output, but yields very similar conclusions about the relationship between the actual and prescribed real rate over the postwar era. 